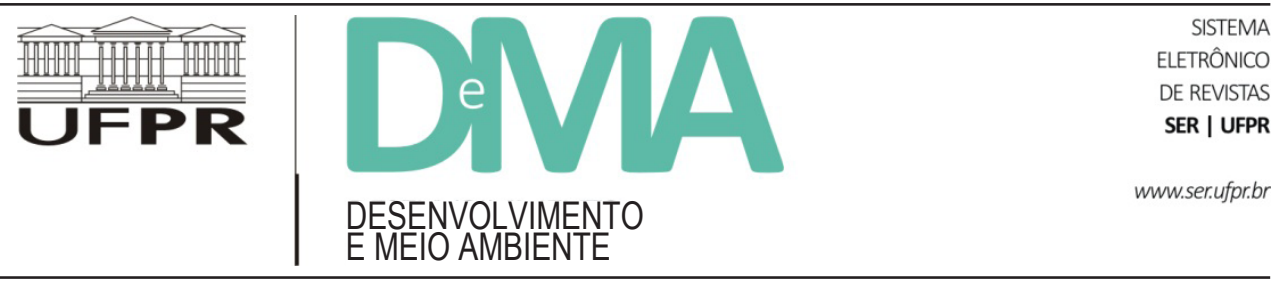

\title{
Análise de possibilidade de expansão das Pequenas Centrais Hidroelétricas no Brasil: um estudo dos limitantes e potencialidades da cadeia produtiva à luz da sustentabilidade
}

\section{Analysis of the Expansion Possibility of Small Central Hydro powers in Brazil: a Study of the Limitations and Potentials of the Production Chain in the Light of Sustainability}

\author{
Christian Luiz da SILVA ${ }^{1,2 *}$, Georgia Alana Andréas NOWAKOWSKI ${ }^{2}$, Alain Hernandez SANTOYO ${ }^{3}$, Victor \\ Ernesto Perez LEON ${ }^{3}$, Mayra Casas VILARDELL ${ }^{3}$ \\ ${ }^{1}$ Programa de Pós-Graduação em Planejamento e Governança Pública (PGP), Universidade Tecnológica Federal do Paraná (UTFPR), Curitiba, \\ PR, Brasil. \\ ${ }^{2}$ Programa de Pós-Graduação em Tecnologia (PPGTE), Universidade Tecnológica Federal do Paraná (UTFPR), Curitiba, PR, Brasil. \\ ${ }^{3}$ Universidad de Pinar del Rio, Pinar del Río, Cuba. \\ *E-mail de contato: christianlsilva76@gmail.com
}

Artigo recebido em 30 de janeiro de 2016, versão final aceita em 28 de abril de 2016.

RESUMO: As pequenas centrais hidroelétricas são estratégicas para a expansão da matriz energética brasileira e a sua expectativa de crescimento consta do Plano Nacional de Energia. Contudo, não é evidente como esta expansão efetivamente poderá ocorrer, considerando que apenas o potencial hidráulico não garante isso. Neste contexto, o principal objetivo dessa pesquisa é identificar os principais limites e potencialidades da sustentabilidade da cadeia produtiva de Pequenas Centrais Hidrelétricas (PCHs) no Brasil, no contexto das dimensões ambiental, social, econômica e institucional. No que tange à metodologia da pesquisa, ela pode ser classificada como aplicada e exploratória. Os dados empregados são secundários e foi utilizada a técnica de análise qualitativa. Para a identificação dos gargalos e potencialidades, foi realizado um mapeamento da estrutura da cadeia de produção das PCHs no país. Em seguida, foram estudadas, de forma mais aprofundada, cinco etapas que compõem a cadeia: recurso natural, geração, transmissão, distribuição e comercialização. Na sequência, foram utilizados cinco critérios (importância, probabilidade, temporalidade, efeito e abrangência) para classificar os fatores identificados em cada etapa. Por fim, estabeleceu-se um critério de agregação e definiu-se um índice de significância para a potencialidade e para o limitante de cada etapa da cadeia. Como resultados, foram identificados 20 limites e 17 potencialidades relacionadas com a cadeia produtiva das PCHs no Brasil. Concluiu-se que para tornar o setor mais competitivo são necessários alguns esforços para reduzir os impactos socioambientais negativos decorrentes da instalação das PCHs, tais como das áreas alagadas e das famílias reassentadas, bem como ajustar alguns aspectos legais e técnicos relacionados com o meio ambiente e a comercialização de ener- 
gia. Por outro lado, o potencial hidráulico e a consolidação dos fabricantes de turbinas e geradores ratificam as PCHs como estratégicas e potenciais para o país.

Palavras-chave: energia renovável; Pequenas Centrais Hidrelétricas; cadeia produtiva; fatores determinantes da competitividade; sustentabilidade.

ABSTRACT: Small hydro power plants are considered strategic in the expansion projects at the National Energy Plan in Brazil. However, it is not clear how this expansion can effectively occur, considering that only hydraulic potential is not sufficient enough to guarantee it. In this sense, the main objective of the present research is to identify the key limitations and potentials of sustainability in the productive chain for Small Hydro Power (SHP) in Brazil, to the context of environmental, social, economic and institutional dimensions. Regarding the research methodology, it can be classified as applied and exploratory. The data used is secondary and was used a qualitative analysis technique. To identify limitations and potentials, a mapping of SHP production chain structure was done at national scale. Five stages that compound the production chain were studied: natural resources; generation; transmission; distribution; and marketing. According to these stages, five criteria were used (importance, probability, timeliness, scope and effect) to classify factors identified in each step. Finally, it is established an aggregations criteria and a significance level for the potential and the limitations of each chain stage was defined. As a result, 20 limiting and 17 potential related to the productive chain of SHPs in Brazil were identified. In order to make the sector more competitive, efforts needed to reduce the negative environmental impacts arising from the power plants installation were found, such as the flooded areas and the resettled families, and the establishment of some legal and technical aspects related to the environment and energy trading. On the other hand, the hydraulic potential and consolidation of turbine manufacturers and generators ratify the SHP as strategic and potential for the country.

Keywords: renewable energy; small hydropower plants; productive chain; competitiveness determinant factors; sustainability.

\section{Introdução}

O aumento da demanda mundial por energia elétrica, somado à crescente movimentação em prol de atividades ecologicamente sustentáveis, tem estimulado os países a buscarem fontes alternativas de fornecimento energético. O desenvolvimento destas fontes tem por objetivo viabilizar o incremento da oferta de energia e, paralelamente, reduzir a dependência mundial de combustíveis fósseis e nuclear. Os principais tipos de fontes renováveis que têm sido pesquisados e desenvolvidos nos últimos anos são a biomassa, a eólica, a solar, a geotérmica e a hidrelétrica (Silva, 2006; Souza \& Silva, 2012; Manzano-Agugliaro et al., 2013).

Como consta no Plano Decenal brasileiro, a projeção é que a demanda por energia conti- nue aumentando nos próximos anos, resultado, principalmente, do crescimento populacional e do aumento do nível do consumo (EPE, 2013). Contudo, tanto Perius \& Carregaro (2012) quanto Manzano-Agugliaro et al. (2013) ressaltam que há a tendência de ficar cada vez mais difícil a implantação de grandes empreendimentos hidrelétricos, o que torna interessante a priorização da avaliação de novas PCHs.

As PCHs têm como vantagem principal uma maior simplicidade na concepção e na operação e geralmente operam a fio d'água (Reis, 2003; Ardizzon et al., 2014). Segundo Reis (2003, p. 70), elas apresentam três características principais: rápida entrada no sistema de potência e flexibilidade para mudar rapidamente a quantidade de energia proporcionada ao sistema; baixos custos de operação, ma- 
nutenção e de produção de energia; e propriedades mais suaves (soft) de inserção ambiental.

Segundo o Banco de Informações de Geração (BIG) da ANEEL (ANEEL, 2016), em abril de 2016 o Brasil possuía no total 4.496 empreendimentos de geração de energia elétrica em operação, totalizando 142.557 MW de potência instalada. Deste total, 457 usinas eram PCHs, que correspondiam a $4.842 \mathrm{MW}$ (3,38\% do total instalado no país).

Entretanto, no Brasil existem dificuldades para legitimar a necessidade e a conveniência das PCHs no fornecimento de energia elétrica. O desestímulo existente aos investidores em potencial é resultado, principalmente, da elevação dos custos dos novos empreendimentos, tendo em vista que o potencial remanescente encontra-se mais distante do centro de consumo, assim como a questão ambiental, o deslocamento da população e a falta de clareza do setor e de alguns órgãos governamentais (Jannuzzi, 2010; Moraes, 2010).

Diante deste cenário, o principal objetivo dessa pesquisa é analisar como está estruturada a cadeia produtiva das $\mathrm{PCHs}$ no Brasil, apresentando os seus gargalos e as suas potencialidades, no contexto das dimensões ambiental, social, econômica e institucional. A metodologia é exploratória, descritiva e qualitativa, com uso de números índices para sustentar a análise. A técnica de coleta de dados foi essencialmente bibliográfica, em documentos primários e secundários. A metodologia está detalhada na seção 3 .

Este trabalho é constituído de seis partes. Após a introdução, o segundo capítulo apresenta a relação entre energia e meio ambiente, para tratar, na sequência, especificamente do tema das pequenas centrais hidrelétricas e como se estrutura a sua cadeia produtiva. Posteriormente, apresenta-se a metodologia para, na seção seguinte, trazer informações sobre as PCHs no Brasil, seguidas dos resultados e das conclusões.

\section{Energia, meio ambiente e Pequenas Centrais Hidrelétricas}

Esta seção tem o objetivo de apresentar os fundamentos sobre energia e desenvolvimento e apresentar as pequenas centrais hidrelétricas e a sua cadeia produtiva.

\subsection{Energia e meio ambiente}

O aumento da população mundial e, consequentemente, a crescente demanda por energia resultaram em uma intensa exploração dos recursos naturais sem que fosse avaliada a capacidade de regeneração dos ecossistemas.

De acordo com Pinto Junior et al. (2007, p. 22), "a importância da oferta e da demanda de energia para o desempenho do sistema econômico é um resultado das múltiplas interações entre as diferentes dimensões que envolvem o setor energético". A Tabela 1 sintetiza o conjunto de dimensões que interagem com o setor de energia.

Para Vianna (2009), o desenvolvimento de fontes renováveis é um caminho favorável para proteger o meio ambiente e, de certa forma, oferece a oportunidade de complementar a oferta descentralizada de energia, gerando benefícios econômicos e sociais. Apesar do alto investimento inicial necessário para a implementação das fontes renováveis ter inibido o seu desenvolvimento durante o século XX, em 2011 elas representavam cerca de 13,3\% do total de energia primária ofertada no mundo e, em termos de geração de eletricidade, foram responsáveis por $20,3 \%$ do total gerado mundialmente (Sauer et al., 2006; ICSHP, 2013). 
TABELA 1 - Dimensões da energia e as interações que envolvem o setor energético.

\begin{tabular}{ll}
\hline \multicolumn{1}{c}{ Dimensões } & \multicolumn{1}{c}{ Interações que envolvem o setor energético } \\
\hline Ambiental & $\begin{array}{l}\text { Como se dá o desenvolvimento sustentável no que tange aos impactos ambientais, ao controle de } \\
\text { emissões de gases de efeito estufa, às mudanças climáticas e às escolhas tecnológicas efetuadas pelas } \\
\text { empresas. }\end{array}$ \\
\hline Social & $\begin{array}{l}\text { Como o setor energético afeta o desenvolvimento regional e que efeitos as políticas públicas desse setor } \\
\text { provocam sobre a população local: trabalho, rendimento, saúde, cultura, educação, habitação, segurança } \\
\text { e a minimização das desigualdades. }\end{array}$ \\
\hline Econômica & $\begin{array}{l}\text { Fontes de financiamento, custos e as interações entre o crescimento regional e os aspectos } \\
\text { macroeconômicos, microeconômicos, tecnológicos e políticas internacionais. }\end{array}$ \\
\hline Institucional & $\begin{array}{l}\text { Orientação política, políticas ambientais, políticas energéticas, capacidade e esforços governamentais e } \\
\text { da sociedade para o alcance do desenvolvimento sustentável. }\end{array}$ \\
\hline
\end{tabular}

FONTE: Adaptado de Pinto Junior et al. (2007, p. 22).

Neste aspecto, a escolha da matriz energética envolve relações e impactos em todos os processos de desenvolvimento de uma região, seja por meio do impacto ambiental, seja pelas implicações sociais, econômicas e as demandas institucionais (Souza \& Silva, 2012).

\subsection{Pequenas Centrais Hidrelétricas (PCHS) e a estrutura da sua cadeia produtiva}

Diferentemente das grandes usinas hidrelétricas, cujo desenvolvimento está associado à construção de grandes barragens, as PCHs, por serem de menor porte, têm como vantagem principal uma maior simplicidade na concepção e na operação. Esses empreendimentos geralmente não utilizam reservatórios para armazenagem de grandes volumes de água e normalmente operam a fio d'água, permitindo a passagem contínua do rio com uma capacidade nominal estável (Reis, 2003; Ardizzon et al., 2014).

As PCHs podem ser utilizadas para a complementação de sistemas de grande porte em função do menor risco de investimento (Makaron, 2012, p. 2). Perius \& Carregaro (2012) afirmam que estas centrais auxiliam na ampliação e na diversificação do setor energético dos países e podem contribuir para o desenvolvimento econômico e social de regiões isoladas. Ademais, as etapas de projeto e implantação deste tipo de empreendimento são mais simples do que as das grandes usinas (Reis, 2003, p. 69).

De acordo com Reis (2003, p. 70), as PCHs possuem três características principais. A primeira está associada à questão de possuir rápida entrada no sistema de potência e flexibilidade para mudar rapidamente a quantidade de energia proporcionada ao sistema, por causa das alterações na demanda. A segunda diz respeito ao fato de que elas apresentam baixos custos de operação, manutenção e de produção de energia. A terceira, e última, refere-se as suas propriedades mais suaves (soft) de inserção ambiental.

As PCHs constituem-se em estruturas hidráulicas construídas nos rios, que proporcionam o aproveitamento dos desníveis para a geração de energia. O processo envolvido na produção de eletricidade em uma PCH depende de inúmeras variáveis, como, por exemplo, a vazão do rio, a quantidade de água disponível em determinado período de tempo, 
os desníveis do terreno, a tecnologia utilizada e a demanda por energia (ANEEL, 2008).

$\mathrm{O}$ princípio fundamental do funcionamento de uma PCH está relacionado com a utilização da uma barragem para represar a água do rio em curso. A água represada aciona uma turbina hidráulica e esta, por sua vez, efetua a transformação da energia hidráulica em mecânica. Em seguida, um gerador elétrico é acionado, transformando energia mecânica em elétrica. A energia elétrica gerada é transmitida e distribuída por meio de linhas de transmissão para os consumidores e a água utilizada é conduzida novamente ao rio (Reis, 2003; Makaron, 2012).

Resumidamente, pode-se separar a cadeia produtiva de uma $\mathrm{PCH}$ em cinco etapas principais: recurso natural; geração; transmissão; distribuição; e comercialização (Tabela 2).

TABELA 2 - Etapas da cadeia produtiva de uma PCH com respectiva função.

\begin{tabular}{ll}
\hline \multicolumn{1}{c}{ Etapa } & \multicolumn{1}{c}{ Função } \\
\hline Recurso Natural & $\begin{array}{l}\text { Fornecer matériaprima para a PCH } \\
\text { Transformar energia hidráulica em } \\
\text { energia elétrica }\end{array}$ \\
Transão & $\begin{array}{l}\text { Transmitir a energia elétrica até os } \\
\text { centros de distribuição }\end{array}$ \\
Distribuição & $\begin{array}{l}\text { Distribuir a energia até os centros } \\
\text { consumidores }\end{array}$ \\
Comercialização & Comercializar a energia gerada \\
\hline
\end{tabular}

FONTE: Autoria própria.

A etapa de recurso natural depende fundamentalmente da disponibilidade de água para o aproveitamento hidrelétrico, tendo em vista que a energia produzida é consequência da dinâmica da água quando ela passa pelas turbinas. Este recurso natural é considerado indispensável para a sobrevivência do ser humano e é uma substância fundamental para os ecossistemas da natureza. Ele é resultado do fenômeno conhecido por ciclo hidrológico (ANEEL, 2003; Carvalho et al., 2007).
A segunda etapa da cadeia consiste fundamentalmente na transformação da energia hidráulica em energia elétrica. A estrutura de uma central hidrelétrica é composta, basicamente, por barragem, sistema de captação e adução de água, casa de força, vertedouro e canal de fuga. Estes elementos funcionam em conjunto e de maneira integrada (INEPAR, 2014). Quando a água passa pelas turbinas hidráulicas e faz com que elas girem, apresentando o mesmo princípio de uma roda d'água, ocorre a transformação da energia hidráulica em mecânica. Após passar pela casa de força, a água é restituída ao leito natural do rio através do canal de fuga, localizado à jusante do tubo de sucção, entre a casa de força e o rio. A energia elétrica gerada é conduzida, por meio de cabos ou barras condutoras, dos terminais do gerador até o transformador elevador (Faria, 2011).

$\mathrm{Na}$ terceira etapa, a energia elétrica gerada na $\mathrm{PCH}$, para ser conduzida até uma subestação, precisa ter sua tensão elevada por um transformador elevador. Quando a eletricidade aproxima-se dos centros de consumo, as subestações diminuem a tensão elétrica, para que ela possa chegar aos domicílios, indústrias e empresas. Na quarta etapa, após percorrer longas distâncias entre as usinas e os centros consumidores, a eletricidade chega em subestações que abaixam a sua tensão, para que possa ser iniciado o processo de distribuição (Eletrobrás, 2005).

A última etapa, a comercialização, tem por objetivo o estímulo à competição no fornecimento de energia elétrica aos consumidores finais. Os agentes comercializadores são empresas que não possuem restrições de posse de ativos ou sistemas elétricos e atuam de forma exclusiva no mercado de compra e venda de eletricidade. 


\section{Metodologia}

A pesquisa é qualitativa e exploratória, quanto aos seus objetivos, e essencialmente descritiva. A técnica de coleta de dados foi principalmente bibliográfica, utilizando apenas dados secundários. As fontes pesquisadas para a obtenção dos dados secundários foram principalmente livros, artigos científicos, dissertações, teses, relatórios, publicações institucionais e também sites de órgãos governamentais.

Para a análise de dados foi necessário delimitar a cadeia de produção a ser analisada, mapeando as etapas que a compõem. Depois de selecionada a etapa a ser estudada, foram identificados os principais fatores determinantes da competitividade envolvidos e observados os limites e potencialidades relacionados à cadeia. Em seguida, estes limites e potencialidades identificados foram classificados conforme a percepção dos autores a partir das leituras e análises realizadas. Para a análise da significância de cada limite e potencialidade identificados neste estudo, foram selecionados cinco critérios:

1) Importância: depende da percepção do agente afetado e pode ser baixa (B), moderada (M) ou alta (A);

2) Probabilidade: está associada à possibilidade de os gargalos e potencialidades ocorrerem efetivamente, podendo ser classificada em ocorrência possível, apesar de incerta (PO), onde não se espera que ocorra, uma vez que depende de falhas múltiplas no sistema, humanas e equipamentos, ou rupturas de equipamentos de grande porte; e certo, ou certeza de ocorrência (CT), quando há ocorrências já registradas ou presume-se que irão ocorrer várias vezes na vida útil do empreendimento;

3) Temporalidade: diz respeito à duração do fator limitante/potencial. Ele pode ser classificado como temporário (T), quando é transitório e passageiro, cíclico (C), quando se repete de tempos em tempos, ou permanente $(\mathrm{P})$, quando a incidência é permanente e estável;

4) Efeito: tem relação à escala temporal do fator analisado e pode ser separado em curto prazo $(\mathrm{CP})$, quando sua influência sobre a cadeia é imediata, e longo prazo (LP), quando dura mais tempo; e

5) Abrangência: considera a dimensão espacial dos itens analisados. Eles podem ser classificados como locais (L), quando a ocorrência é localizada nas imediações da fonte geradora; regionais $(\mathrm{R})$, quando está relacionada com as localidades e municípios próximos; ou estratégicos (E), quando assume proporções em escala estadual, nacional ou global.

A Tabela 3 apresenta uma síntese dos critérios utilizados e os índices atribuídos a eles. Estes índices referem-se à característica de cada aspecto avaliado, como tratado na sua descrição. A atribuição do índice para cada aspecto em cada etapa da cadeia foi definida pelos pesquisadores a partir de ponderações à luz da descrição dos fatores de cada etapa, caracterizados na seção 5 . O detalhamento dos índices atribuídos por aspecto e por etapa da cadeia como limitante ou potencialidade está no Apêndice 1. 
TABELA 3 - Critérios para análise dos limites e potencialidades

\begin{tabular}{llc}
\hline \multicolumn{1}{c}{ Aspecto } & \multicolumn{1}{c}{ Classificação } & Índice \\
\hline \multirow{4}{*}{ Importância (I) } & B: baixa & 1 \\
& M: moderada & 2 \\
& A: alta & 3 \\
\hline & PO: ocorrência possível, & 1 \\
Probabilidade (P) & apesar de incerta & \\
& CT: certo, ou certeza de & 2 \\
& ocorrência & 1 \\
Temporalidade (T) & T: temporário & 2 \\
& C: cíclico & 3 \\
\hline \multirow{2}{*}{ Efeito (E) } & P: permanente & 1 \\
& CP: curto prazo & 2 \\
\hline \multirow{3}{*}{ Abrangência (A) } & LP: longo prazo & 1 \\
& L: local & 2 \\
& R: regional & 3 \\
\hline
\end{tabular}

Para qualificar os limites e potencialidades, os critérios se agregaram em um indicador composto, denominado Índice de Significância (IS). Na literatura há vários métodos diferentes para a criação de indicadores compostos, como em Organização para a Cooperação Econômica e Desenvolvimento - OCDE (2008); no entanto, pode-se dizer que não existe uma metodologia como a mais bem sucedida para a sua criação (Pérez et al., 2013). Neste sentido, os pesquisadores recorrem ao melhor método que representa o fenômeno a ser medido.

Para este estudo, determinou-se o IS dos limites e potencialidades, que foi definido pela multiplicação de índices numéricos atribuídos a diversos critérios elevados ao exponencial, conforme equação 1 , sendo estabelecido o sinal positivo para quando se trata de potencialidade e negativo quando se trata de limitante. Este sinal tem o propósito de expor graficamente os limites e potencialidades para o leitor.

IS Potencialidade $e_{\text {etapa } X}=\exp { }^{\left(\frac{V I}{3} * \frac{V P}{2} * \frac{V T}{3} * \frac{V E}{2} * \frac{V A}{3}\right)}-1$
IS Limitante etapa $X=-\exp { }^{\left(\frac{V I}{3} * \frac{V P}{2} * \frac{V T}{3} * \frac{V E}{2} * \frac{V A}{3}\right)}+1$

(Equação 2)

Sendo: VI = Valor atribuído à Importância; VP = Valor atribuído à Probabilidade; VT = Valor atribuído à Temporalidade; $\mathrm{VE}=$ valor atribuído ao Efeito; $\mathrm{VA}=$ Valor atribuído à Abrangência. IS = Índice de Significância. Etapa $\mathrm{x}=$ refere-se à etapa da cadeia de produção, conforme o Quadro 2.

Nota: Limite superior para IS potencialidade $=\mathbf{1 . 7}$ (trata-se de um fator que possibilita naquela etapa da cadeia um potencial relevante para o desenvolvimento da fonte energética por PCHs); Limite inferior para IS potencialidade $=\mathbf{0}$ (trata-se de um fator que possibilita naquela etapa da cadeia um potencial irrelevante para o desenvolvimento da fonte energética por PCHs); Limite superior para IS limitante $=\mathbf{0}$ (trata-se de um fator que não representa uma limitação significativa naquela etapa da cadeia para o desenvolvimento da fonte energética por PCHs); Limite inferior para IS limitante $=\mathbf{- 1 . 7}$ (trata-se de um fator que limita significativamente naquela etapa da cadeia para o desenvolvimento da fonte energética por PCHs). Considera-se o fator como muito significativo quando igual a 0,64 , em termos absolutos, sendo o sinal representativo de um limitante (negativo) ou potencialidade (positivo). Este valor representa a média ponderada em todos os critérios.

Tem-se com isso dois produtos: as figuras com os limitantes e potencialidades por etapa da cadeia (Figuras 2 a 6) e uma Tabela síntese dos índices atribuídos (Apêndice 1).

(Equação 1) 


\section{Panorama das Pequenas Centrais Hidrelétricas no Brasil}

A matriz energética brasileira é conhecida internacionalmente pelo alto percentual de participação das fontes renováveis, em especial pela utilização de empreendimentos hidrelétricos na produção de eletricidade, em virtude da abundância dos recursos hídricos existentes no país (Fontes et al., 2010, p. 7).

Segundo dados obtidos no Banco de Informações de Geração (BIG) da ANEEL (2016), no período de 2002 a 2012 a capacidade instalada das PCHs no Brasil aumentou de 895 MW para 4.248 MW. Este crescimento representou um incremento da sua participação na capacidade total do país de $1,1 \%$ para aproximadamente $3,5 \%$.

Em abril de 2016, o Brasil possuía no total 4.496 empreendimentos de geração de energia elétrica em operação, totalizando 142.557 MW de potência instalada. Deste total, 457 usinas eram PCHs que correspondiam a $4.842 \mathrm{MW}(3,38 \%$ do total instalado no país). Ademais, existiam 43 empreendimentos em construção (499 MW) e 130 outorgados (1.889 MW), mas com a construção não iniciada, resultando em uma adição futura de 2.388 MW na capacidade de geração brasileira. A fonte mais representativa continua sendo a oriunda de usinas hidroelétricas (61\%), seguido das usinas termoelétricas $(28 \%)$ e da geração por centrais eólicas $(6 \%)$ - (Tabelas 4 e 5).

TABELA 4 - Empreendimentos em operação no Brasil, por tipo abr./2016.

\begin{tabular}{lllll}
\hline Tipo & $\begin{array}{c}\text { Quanti- } \\
\text { dade }\end{array}$ & $\begin{array}{c}\text { Potência } \\
\text { Outorgada } \\
(\mathbf{k W})\end{array}$ & $\begin{array}{c}\text { Potência } \\
\text { Fiscalizada } \\
(\mathbf{k W})\end{array}$ & \multicolumn{1}{c}{$\%$} \\
\hline CGH & 556 & 429.181 & 431.084 & 0,30 \\
EOL & 354 & 8.643 .268 & 8.592 .590 & 6,03 \\
PCH & 457 & 4.842 .727 & 4.825 .445 & 3,38 \\
UFV & 38 & 26.933 & 22.933 & 0,02 \\
UHE & 203 & 89.490 .541 & 87.136 .428 & 61,12 \\
UTE & 2.886 & 41.311 .215 & 39.558 .330 & 27,75 \\
UTN & 2 & 1.990 .000 & 1.990 .000 & 1,40 \\
Total & 4.496 & 146.734 .165 & 142.556 .630 & 100 \\
\hline
\end{tabular}

FONTE: Adaptado de ANEEL (2016).

NOTA: CGH: Central Geradora Hidrelétrica; EOL: Central Geradora Eólica; PCH: Pequena Central Hidrelétrica; UFV: Central Geradora Solar Fotovoltaica; UHE: Usina Hidrelétrica; UTE: Usina Termelétrica; e UTN: Usina Termonuclear.

TABELA 5 - Empreendimentos em construção e com construção não iniciada no Brasil, por tipo - abr./2016.

\begin{tabular}{ccccccc}
\hline Tipo & Quantidade & $\begin{array}{c}\text { Em construção } \\
\text { Potência Outorgada } \\
(\mathbf{k W})\end{array}$ & $\mathbf{\%}$ & Quantidade & $\begin{array}{c}\text { Construção não iniciada } \\
\text { Potência Outorgada } \\
\mathbf{( k W )}\end{array}$ & $\mathbf{\%}$ \\
\hline CGH & 1 & 848 & 0 & 41 & 30.279 & 0,17 \\
CGU & - & - & - & 1 & 50 & 0 \\
EOL & 148 & 3.458 .074 & 16,4 & 249 & 5.977 .250 & 33,37 \\
PCH & 37 & 509.901 & 2,4 & 124 & 1.776 .076 & 9,92 \\
UHE & 10 & 13.456 .242 & 63,8 & 6 & 629.000 & 3,51 \\
UFV & 0 & 0 & 0 & 66 & 1.881 .645 & 10,5 \\
UTE & 23 & 2.328 .569 & 11,0 & 136 & 7.617 .598 & 42,53 \\
UTN & 1 & 1.350 .000 & 6,4 & & & 17.911 .898 \\
Total & 220 & 21.103 .634 & 100 & 623 & & 100 \\
\hline
\end{tabular}

FONTE: Adaptado de ANEEL (2016).

Nota: CGH: Central Geradora Hidrelétrica; CGU: Central Geradora Undielétrica; EOL: Central Geradora Eólica; PCH: Pequena Central Hidrelétrica; UFV: Central Geradora Solar Fotovoltaica; UHE: Usina Hidrelétrica; UTE: Usina Termelétrica; e UTN: Usina Termonuclear. 
No que se refere à perspectiva de desenvolvimento das PCHs, as projeções da Empresa de Pesquisa Energética (EPE), contidas no Plano Decenal de Expansão de Energia, preveem que o potencial total instalado das PCHs, até o ano de 2022, será de 6.905 MW, o que irá representar cerca de 3,8\% da capacidade total do país (Figura 1). Entretanto, observa-se que a participação das outras fontes renováveis, eólica e biomassa, será superior à das PCHs. Uma das razões para este fato refere-se ao custo da energia elétrica gerada por estas fontes. Enquanto que os custos de energia eólica e da biomassa adicionadas ao sistema são de R $\$ 100 / \mathrm{MWh}$ e $\mathrm{R} \$ 102 / \mathrm{MWh}$, respectivamente, os custos das PCHs são de R\$156/MWh (EPE, 2011).

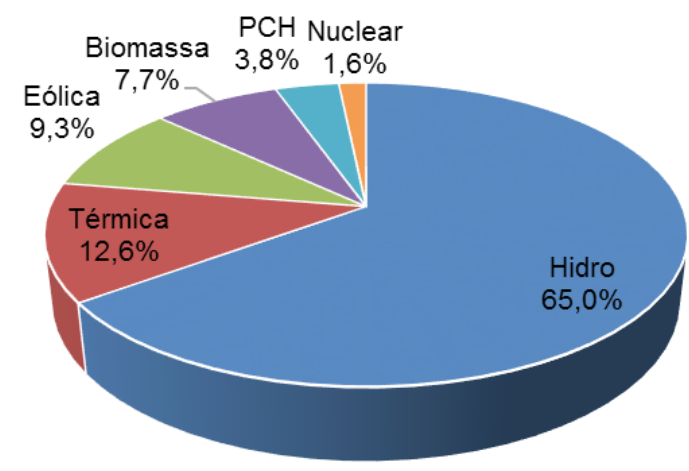

FIGURA 1 - Previsão da participação percentual da capacidade instalada por tipo de fonte geradora no Brasil para 2022. FONTE: EPE (2013).

Por mais que a implementação de PCHs não resolva as necessidades de geração de eletricidade no país, "é inegável que o Brasil poderá aumentar a capacidade de geração por meio das PCHs, privilegiando projetos de geração para sistemas isolados e atendimento às comunidades e propriedades rurais não energizadas" (Bermann, 2007, p. 151). Além disso, os custos com a instalação de grandes linhas de transmissão tendem a diminuir, já que as usinas estarão mais próximas dos centros consumidores (Makaron, 2012, p. 6).

\section{Análise de cadeia produtiva de PCHS no Brasil}

A seguir, apresentam-se os resultados da pesquisa por etapa da cadeia, conforme descrito na segunda seção, para, na seção 5.6, detalhar os principais limitantes, potencialidades e proposições.

\subsection{Etapa 1 - Recurso Natural}

Dentre os dispositivos legais criado pelo governo com o intuito de gerenciar a oferta e a demanda dos recursos hídricos, destaca-se a Lei $n^{\circ} 9.433$, de 8 de janeiro de 1997. Esta Lei define como competência da União a instituição do sistema nacional de gerenciamento de recursos hídricos e a definição dos critérios de outorga de direitos de seu uso. Ela institui ainda a Política Nacional de Recursos Hídricos (PNRH) e o Sistema Nacional de Gerenciamento de Recursos Hídricos (SNGRH), com o objetivo de assegurar às futuras gerações a necessária disponibilidade de água com fins de subsidiar a preservação e a infraestrutura da bacia hidrográfica (Fontes et al., 2010, p. 6).

Depois de observados os principais arranjos institucionais que regulamentam o uso dos recursos hídricos, para que sejam realizados os estudos para implantação de uma $\mathrm{PCH}$, é preciso estimar o potencial hidrelétrico da sua bacia hidrográfica (EPE, 2014, p. 120). Para avaliar o potencial e a estimativa de custo do aproveitamento da bacia hidrográfica, são realizadas análises preliminares das características da bacia, especialmente quanto aos aspectos topográficos, hidrológicos, geológicos e ambientais (MME, 2007, p. 24). 
Depois de estudados o potencial e a estimativa do aproveitamento da bacia hidrográfica, para que a PCH seja implantada são necessários a remoção da vegetação e o alagamento da Área Diretamente Afetada (ADA). O alagamento realizado pelas usinas resulta em supressão da vegetação da $\mathrm{ADA}$, o que causa impactos à fauna e flora local e imediatamente próxima. A inundação causa diminuição dos recursos dentro área de vida das espécies, ocasionando redução da oferta de alimento e da disponibilidade de espaço para o desenvolvimento de alguma etapa do seu ciclo de vida (IAP, 2011, p. 388).

Além dos impactos sobre o ecossistema, o alagamento de áreas cobertas por vegetação altera o processo de troca de gases com a atmosfera. Em 2010, a emissão dos gases do efeito estufa no Brasil chegou a 1,246 Gt $\mathrm{CO}_{2}$ eq, sendo que o setor de geração de eletricidade contribui com 32\% das emissões, ficando atrás apenas do setor agropecuário, com $35 \%$.

O alagamento necessário para a construção das PCHs pode ocasionar também possíveis perdas de heranças históricas e culturais por meio da destruição parcial de sítios arqueológicos. Conforme a World Commission on Dams (WCD) (2000, p. 116), a construção de barragens pode gerar efeitos adversos significativos sobre os patrimônios culturais por meio da perda de recursos locais culturais (templos, santuários e elementos sagrados da paisagem, artefatos e construções) e da submersão e da degradação dos recursos arqueológicos (restos vegetais e animais, cemitérios e elementos arquitetônicos).

$\mathrm{O}$ enchimento dos reservatórios pode resultar ainda na necessidade de reassentamentos dos moradores que residirem na ADA. Conforme Souza et al. (2001, p. 10), apesar do reassentamento populacional "ser um dos componentes menos pesquisados na criação de reservatórios artificiais, ocorre com frequência e é muito importante para o sucesso de projetos de construção de represas que criam lagos artificiais". A transferência da população pode gerar também insatisfação e resistência quanto à instalação dos empreendimentos. Paralelamente à necessidade de reassentamento dos moradores, o alagamento de parte das propriedades do entorno dos rios e a área necessária para formação da APP pode comprometer parcial ou totalmente o desenvolvimento de determinadas atividades produtivas na ADA.

Entre os possíveis desdobramentos da instalação das $\mathrm{PCH}$ nas propriedades localizadas na ADA pode-se citar a desmobilização de infraestrutura edificada, assim como a redução de parcela substancial de área produtiva, comprometendo a continuidade da atividade econômica (Leão, 2008, p. 147; IAP, 2011, p. 411). Por outro lado, apesar de os aproveitamentos hidrelétricos comprometerem algumas atividades econômicas, tais como a agricultura e o extrativismo madeireiro, eles tendem a gerar também emprego e renda temporários nos municípios da Área de Influência Direta (AID). Entretanto, para que isso aconteça é necessário que haja, por parte dos empreendedores, a priorização da contratação de mão de obra local.

A Figura 2 apresenta os resultados do índice de significância calculados a partir dos dados do Apêndice 1 para os recursos naturais, conforme as equações 1 e 2, discorridas na metodologia. Pode-se observar que há mais limitantes que potencialidades ( 7 contra 5) e os limitantes são mais representativos. A maior limitação é o licenciamento ambiental (valor limite da escala), mas o reassentamento também é um gargalo relevante. Do outro lado, o principal potencial refere-se justamente ao item que inclui as PCHs como fonte estratégica para a matriz energética brasileira: o potencial hidroelétrico. Contudo, este potencial não atinge o limite da escala $(1,7)$ porque este potencial hidroelétrico é muito variável e depende de condições climáticas. 


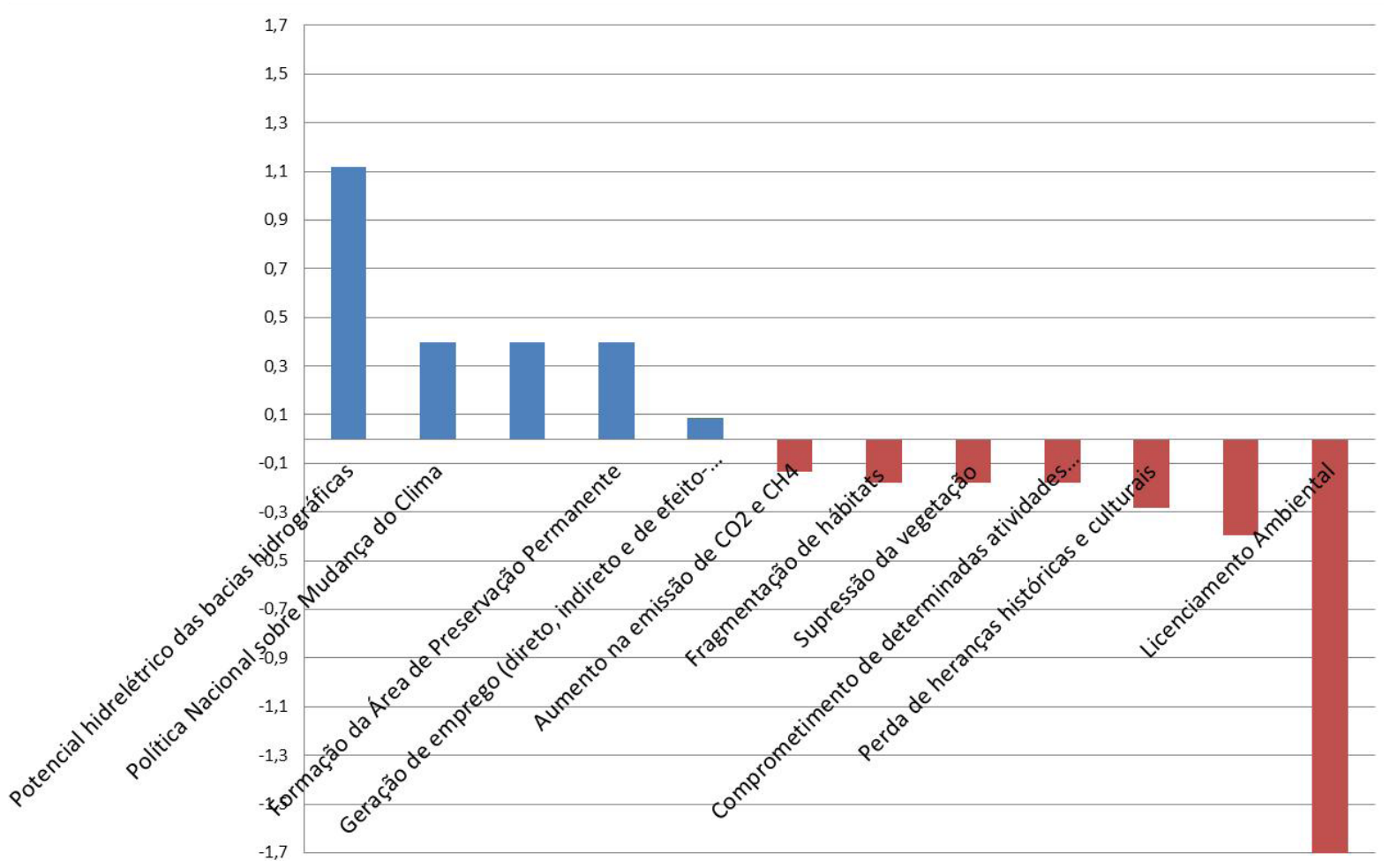

FIGURA 2 - Índice de Significância da Cadeia de PCHs - Recursos Naturais.

Legenda: Azul = Potencialidade para o desenvolvimento da Energia por PCHs; Vermelho = Limitante para o desenvolvimento da Energia por PCHs.

NOTA: Cálculos produzidos a partir dos itens da metodologia e do resultado detalhado no Apêndice 1.

\subsection{Etapa 2 - Geração}

Um dos fatores limites do funcionamento das usinas está associado ao potencial das PCHs em alterarem a qualidade da água superficial do rio, tendo em vista que a formação de um reservatório altera a morfologia de um corpo hídrico. Processos erosivos, descaracterização da vegetação da área de preservação permanente e lançamento de esgoto também contribuem para esta alteração, gerando o aumento de nutrientes, da turbidez e de sedimentos na água (IAP, 2011, p. 399).

Além da possível deterioração da qualidade da água, o processo de geração de energia pode influenciar negativamente a população dos peixes, sendo que a variação no fluxo da água à jusante do barramento pode interferir nos seus comportamentos migratórios e na sua reprodução (Capellesso \& Cazella, 2011, p. 15). Visando minimizar os impactos negativos sobre a ictiofauna, alguns mecanismos podem ser construídos, como os de transposição e de repulsão de peixes (Kusma \& Ferreira, 2010, p. 90; Andrade \& Araújo, 2011, p. 1).

Apesar de as PCHs poderem causar impactos negativos sobre a qualidade da água e a população dos peixes, comprometendo atividades pesqueiras, os seus reservatórios podem ser utilizados para atender usos múltiplos integrados. O uso múltiplo 
das águas consiste em um dos fundamentos da Política Nacional de Recursos Hídricos e, dentre os possíveis aproveitamentos múltiplos, podem ser citados: abastecimento urbano; produção de fertilizantes; navegação; controle de enchentes. Em contrapartida aos usos múltiplos integrados, a construção de reservatórios pode representar riscos à população residente no entorno dos empreendimentos, devido aos possíveis acidentes e rupturas que podem ocorrer nas barragens, como citam Barbosa et al. (2011, p. 23).

As principais causas dos rompimentos podem estar associadas tanto aos aspectos materiais quanto aos humanos, dentre os quais se destacam as falhas nas fundações, os efeitos sísmicos, os erros no projeto e as falhas na construção. Apesar de a probabilidade de rompimento ser pequena, para que o risco seja minimizado é necessário que sejam elaborados um Plano de Ação de Emergência (PAE), uma Análise de Risco e um Estudo de Rompimento da Barragem (Vadas, 2014).

Embora as PCHs apresentem alguns riscos, elas também podem proporcionar o melhor atendimento às necessidades de consumo de pequenas regiões urbanas e localidades rurais. A geração distribuída, ou descentralizada, que se caracteriza por produzir menor capacidade e ser conectada na rede local de distribuição de energia próxima aos centros de consumo, diminui os custos com a transmissão de energia e pode promover o desenvolvimento regional (Vergílio, 2012, p. 29).

Conforme The World Bank (2016), em 2012 a média da população brasileira com acesso à eletricidade era de 99,5\%, ficando acima da média mundial, de $84,6 \%$. Entretanto, verifica-se que esta distribuição é desigual entre as áreas urbanas e rurais. Segundo o Censo Demográfico de 2010, enquanto na área urbana apenas $0,27 \%$ (133 mil) dos domicílios não tinham acesso à energia elétrica, na área rural este percentual subiu para 7,3\% (595 mil domicílios).

Nadaud (2012, p. 4) afirma que a energia elétrica tem um papel fundamental na transformação da sociedade rural, tendo em vista que o acesso a esse serviço aumentou a qualidade de vida da população e possibilita a inserção do produtor rural no mercado por meio do uso de técnicas mais eficazes de produção. Ademais, a aquisição de eletrodomésticos e equipamentos rurais elétricos, com o seu uso facilitado devido ao acesso à energia elétrica, pode favorecer a permanência da família no campo, reduzindo o fluxo migratório para as grandes cidades.

A WWF Brasil (2006, p. 45) destaca que o mercado nacional possui fabricantes que podem fornecer quase a totalidade dos equipamentos para PCHs. De acordo com o CERPCH (2015a), a indústria nacional de turbinas está apta para fabricar diferentes tipos de modelos, tais como a Pelton (com injetores simples ou múltiplos), Michell-Banki (com ou sem tubo de sucção), a Francis (com rotores simples e geminado) e a Kaplan, com distintos arranjos, como caixa espiral, aberta ou cilíndrica.

A Figura 3 demonstra um equilíbrio de fatores que tornam potencial ou limitam o desenvolvimento das PCHs, entretanto, o fator mais significativo é positivo e se refere à consolidação dos fabricantes de turbinas e geradores, que não é mais relevante por ser uma condição de curto prazo pela dinâmica do mercado. A potencialidade para o desenvolvimento regional também é um fator de destaque e positivo, contudo, é incerto e não se pode ter garantia de ocorrência. O principal limitante é a interferência na migração e na reprodução da ictiofauna continental, que só não é mais significativa porque a temporalidade é cíclica. 


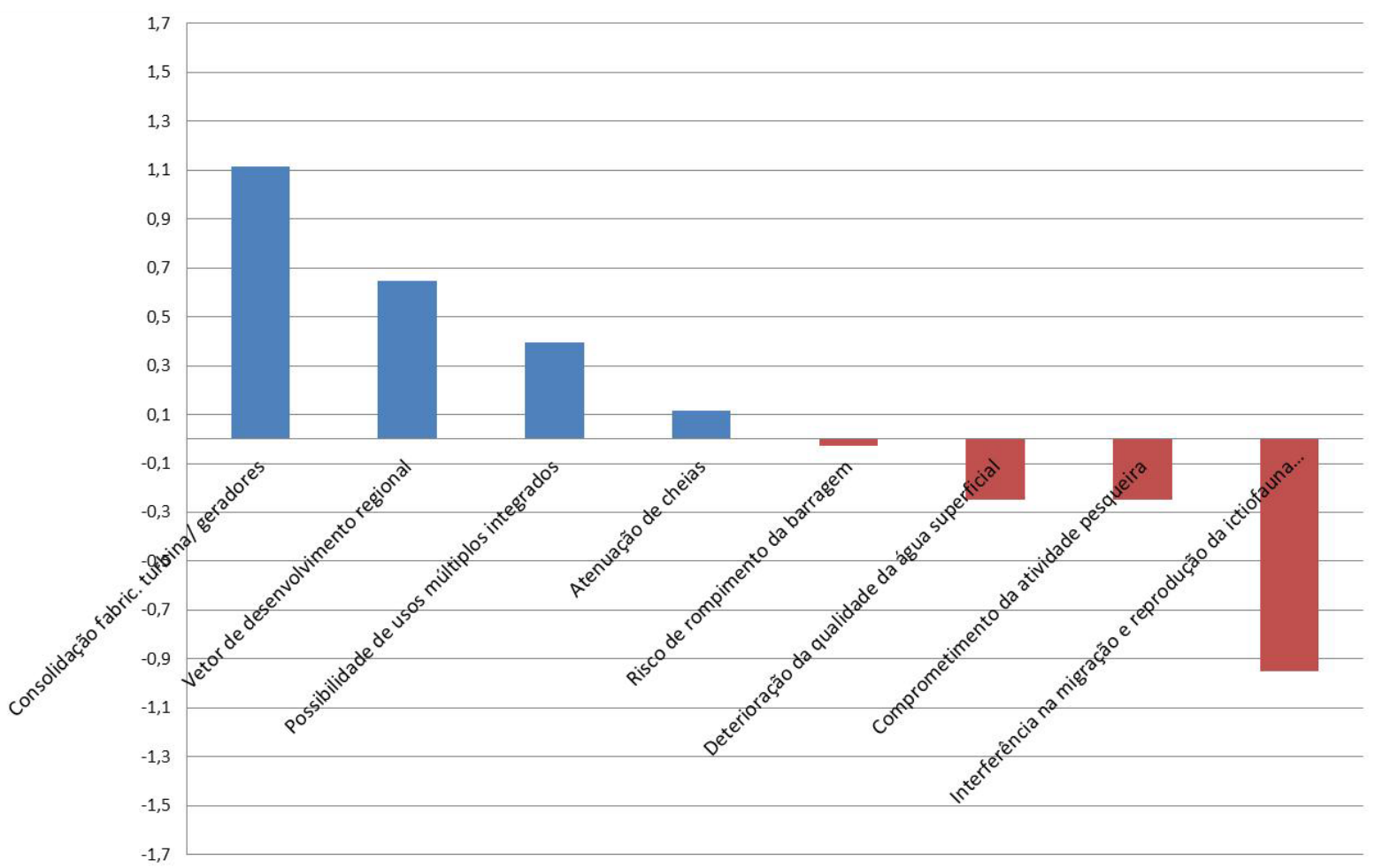

FIGURA 3 - Índice de Significância da Cadeia de PCHs - Geração.

Legenda: Azul = Potencialidade para o desenvolvimento da Energia por PCHs; Vermelho = Limitante para o desenvolvimento da Energia por PCHs.

NOTA: Cálculos produzidos a partir dos itens da metodologia e do resultado detalhado no Apêndice 1.

\subsection{Etapa 3 - Transmissão}

Após a energia elétrica ser gerada pela usina, ela deve ser transmitida, por meio de linhas de transmissão (LTs), até os centros consumidores. O Estado precisa criar um arranjo institucional que assegure o desenvolvimento desta infraestrutura (Francisco, 2012, p. 3). No Brasil, a transmissão da energia é realizada por cerca de 77 concessionárias, que adquirem o direito por meio de leilões efetuados pela ANEEL (Instituto ABRADEE, 2010, p. 8). A atividade de transmissão é regulada pela ANEEL e as concessionárias são responsáveis pela adequada prestação do serviço, bem como pela execução de reforços nas instalações existentes (Vieira, 2009, p. 11). Conforme disposto na Lei $n^{\circ} 9.074$, de 7 de julho de 1995, a concessão é válida por 30 anos, podendo ser renovada por igual período. A lei também dispõe que a transmissão tem como premissa a garantia do livre acesso à rede, mediante ressarcimento dos custos de transporte envolvido (Brasil, 1995).

Atualmente, o Sistema Interligado Nacional (SIN) estende-se sobre a maior parte do território brasileiro e tem por objetivo possibilitar o intercâmbio de energia entre as diferentes regiões (Eletrobrás, 2005; Vieira, 2009, p. 9; Portal Brasil, 2011). 
Ribeiro (2014, p. 26), baseando-se no método de preços da ANEEL (2005), verifica que o custo médio de uma LT de 100 metros varia de 79,4 a 86,9 milhões de reais, conforme a região na qual ela é instalada, sendo que o custo no Sul é o mais baixo e no Sudeste, o mais alto. Dos itens contabilizados pelo autor, um dos mais caros foram os cabos condutores, que apresentaram um custo médio de 32,2 milhões de reais.

Apesar dos altos custos envolvidos na instalação das LTs, os investimentos em grandes linhas de transmissão de energia elétrica foram responsáveis pela elevação da capacidade de produção da indústria brasileira de fios e cabos de alumínio. O Brasil é considerado o oitavo maior produtor de alumínio primário e, diante do crescimento da demanda por fios e cabos, a capacidade instalada da indústria nacional passou de 135 mil toneladas por ano, em 2012, para 190 mil toneladas por ano, em 2014 (Portos e Navios, 2014).

Além de poder ser integrada ao SIN, a energia gerada pelas PCHs pode ser também utilizada em sistemas isolados, nos quais a energia é consumida por apenas uma determinada localidade ou até mesmo por uma só indústria (Nascimento Junior \& Gopfert, 2010, p.16). Este tipo de consumo apresenta vantagens em relação à conexão de centros consumidores distantes do empreendimento, pois diminui as perdas técnicas de energia ocorridas na rede de transmissão (Vergílio, 2012, p. 11).

Apesar de serem capazes de transmitir energia tanto para grandes centros consumidores quanto para comunidades mais próximas do empreendimento, atuando como um vetor para o desenvolvimento das áreas mais isoladas, as linhas de transmissão (LTs), quando energizadas, tendem a provocar efeitos eletromagnéticos. Dentre os principais efeitos destacam-se: os campos elétrico e magnético; a radiointerferência; e o ruído audível. Visando evitar riscos à segurança da linha e aos eventuais obstáculos existentes ao longo do seu traçado, ou até mesmo a exposição humana a esses efeitos, faz-se necessário que essas linhas sejam instaladas dentro de uma área de terra, com uma largura definida, denominada faixa de segurança (Souza, 2012, p. 1; Vergílio, 2012, p. 1).

Em 23 de março de 2010, foram regulamentados no Brasil, por meio da Resolução Normativa $n^{\circ} 398$ da ANEEL, os limites à exposição humana a campos elétricos e magnéticos originários de instalações de geração, transmissão e distribuição de energia elétrica, na frequência de $60 \mathrm{~Hz}$. Em 2014, a Resolução no 398 foi alterada pela Resolução $n^{\circ} 616$, aumentando os níveis de referência estabelecidos.

Além de riscos de exposição humana a campos eletromagnéticos, a instalação das LTs resulta também em supressão da vegetação existente na área da faixa de segurança. A limpeza da faixa altera não apenas os aspectos da flora da região, mas também pode provocar modificações nas populações da fauna presente na ADA e na AID do empreendimento. Tais alterações resultam em mudanças na estrutura e na dinâmica do ecossistema (Nascimento Junior \& Gopfert, 2010, p. 56).

Sales (2011) destaca que o licenciamento ambiental é considerado um dos maiores entraves na implantação das linhas de transmissão. Apesar de o impacto ambiental das linhas ser relativamente baixo, a análise requerida para a obtenção do licenciamento ambiental é muito complexa, por envolver longos trajetos que frequentemente atravessam diversos biomas em várias jurisdições.

A Figura 4 demonstra que tanto as potencialidades quanto os limitantes na etapa da transmissão não são significativos, o que demonstra que é uma etapa já desenvolvida, inclusive porque é comum a qualquer outra fonte de energia. São nove fatores, 
sendo quatro potencialidades e cinco limitantes. Os limitantes destacados são custo de instalação das linhas de transmissão, risco de exposição humana a campos elétricos e magnéticos, restrição de uso da faixa de servidão, supressão da vegetação na faixa de segurança e licenciamento ambiental. As potencialidades são: contribuição ao sistema interligado nacional, livre acesso, indústria nacional de fios e cabos de alumínio em expansão e possível vetor de desenvolvimento regional. O livre acesso é a maior potencialidade, que se refere ao direito de todos os prestadores de serviço público de energia elétrica de utilizarem as redes de transmissão para transportar energia desde os pontos de produção até os consumidores, mas não é significativo.

\subsection{Etapa 4 - Distribuição}

A etapa de distribuição caracteriza-se como a atividade do setor elétrico dedicada à entrega de energia para o consumidor final. De maneira geral, o sistema de distribuição pode ser considerado como o conjunto de instalações e equipamentos elétricos que operam, normalmente, em tensões inferiores a $230 \mathrm{kV}$, incluindo os sistemas de baixa tensão (ANEEL, 2015). O sistema de distribuição é

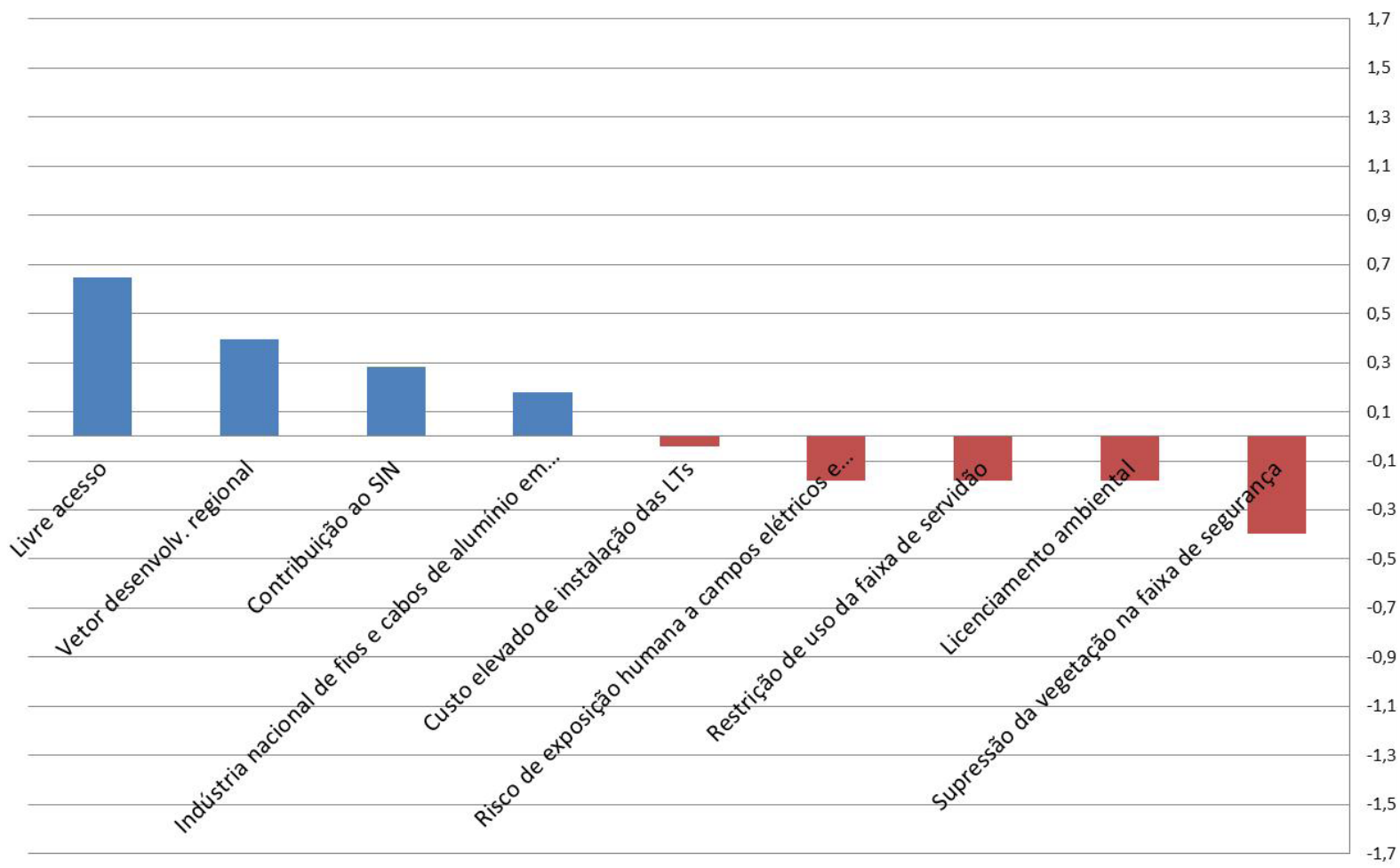

FIGURA 4 - Índice de Significância da Cadeia de PCHs - Transmissão.

Legenda: Azul = Potencialidade para o desenvolvimento da Energia por PCHs; Vermelho = Limitante para o desenvolvimento da Energia por PCHs.

NOTA: Cálculos produzidos a partir dos itens da metodologia e do resultado detalhado no Apêndice 1. 
mais ramificado que o de transmissão, pois precisa atender todos os seus consumidores (ABRADEE, 2015).

Atualmente, segundo a ANEEL (2015), o país possui 63 concessionárias do serviço público de distribuição de energia elétrica, além de um conjunto de permissionárias, que consistem em cooperativas de eletrificação rural que passaram pelo processo de enquadramento como permissionária de serviço público de distribuição de energia elétrica. As condições gerais de contratação do acesso, compreendendo o uso e a conexão, ao sistema de distribuição de energia encontram-se dispostas na Resolução ANEEL n 281, 01 de outubro de 1999.

Não apenas a oferta do serviço público de distribuição de energia deve ser considerada pelas distribuidoras, mas também a questão da desigualdade desta distribuição. Conforme o Programa das Nações Unidas para o Desenvolvimento (PNUD) (2011), 75\% da população mais pobre do mundo utiliza apenas $10 \%$ da oferta global, sendo que $85 \%$ das pessoas sem acesso ao recurso vivem em áreas rurais.

No Brasil, apesar da obrigatoriedade das concessionárias de participarem dos programas governamentais de universalização, o atendimento à população rural não apresentou avanço até o início do século XXI. Visando reverter esta situação, a ANEEL instituiu metas de universalização para as concessionárias distribuidoras de energia elétrica para todos os municípios do país segundo suas áreas de concessão, tendo como base institucional a Lei $\mathrm{n}^{\mathrm{o}}$ 10.438/2002 (Nadaud, 2012, p. 25). Levando em consideração que as PCHs normalmente se localizam longe dos grandes centros consumidores, as suas ligações com as redes rurais de distribuição podem auxiliar na promoção do desenvolvimento de comunidades isoladas.
Para supervisionar a qualidade dos serviços de energia elétrica, são utilizados indicadores técnicos de qualidade, tais como o indicador de Duração Equivalente de Interrupção por Consumidor (DEC) e de Frequência Equivalente de Interrupção por Consumidor (FEC) (ANEEL, 1999, p. 3).

Outro fator competitivo importante que as concessionárias de distribuição de energia elétrica de países emergentes enfrentam é a perda de receita causada por perdas de energia não técnicas. Estas perdas, também chamadas de perdas comerciais, podem ser ocasionadas por equipamentos defeituosos, por erros de leitura e erros de processamento. Entretanto, as principais causas destas perdas são as fraudes e os furtos de energia (Hernandes Junior et al., 2013, p. 48).

No Brasil, em termos monetários, em 2007 os custos das perdas não técnicas chegaram a aproximadamente US\$ 20 bilhões, cerca de 15\% do total de energia distribuída no país (Hernandes Junior et al., 2013, p. 48). Além dos custos econômicos, o furto de energia pode gerar a interrupção do fornecimento de energia e colocar em risco a vida das pessoas, através de incêndios e choques elétricos.

A Figura 5 demonstra que tanto as potencialidades quanto os limitantes na etapa da distribuição não são significativos pelos mesmos motivos da transmissão. São quatro fatores, sendo duas potencialidades e dois limitantes. Os limitantes destacados são desigualdade de distribuição e perdas não técnicas de energia, enquanto as potencialidades são possível vetor de desenvolvimento regional e melhoria na qualidade dos serviços.

\subsection{Etapa 5 - Comercialização}

Segundo a ANEEL (2003, p. 13), a atividade de comercialização constitui-se em uma forma de 


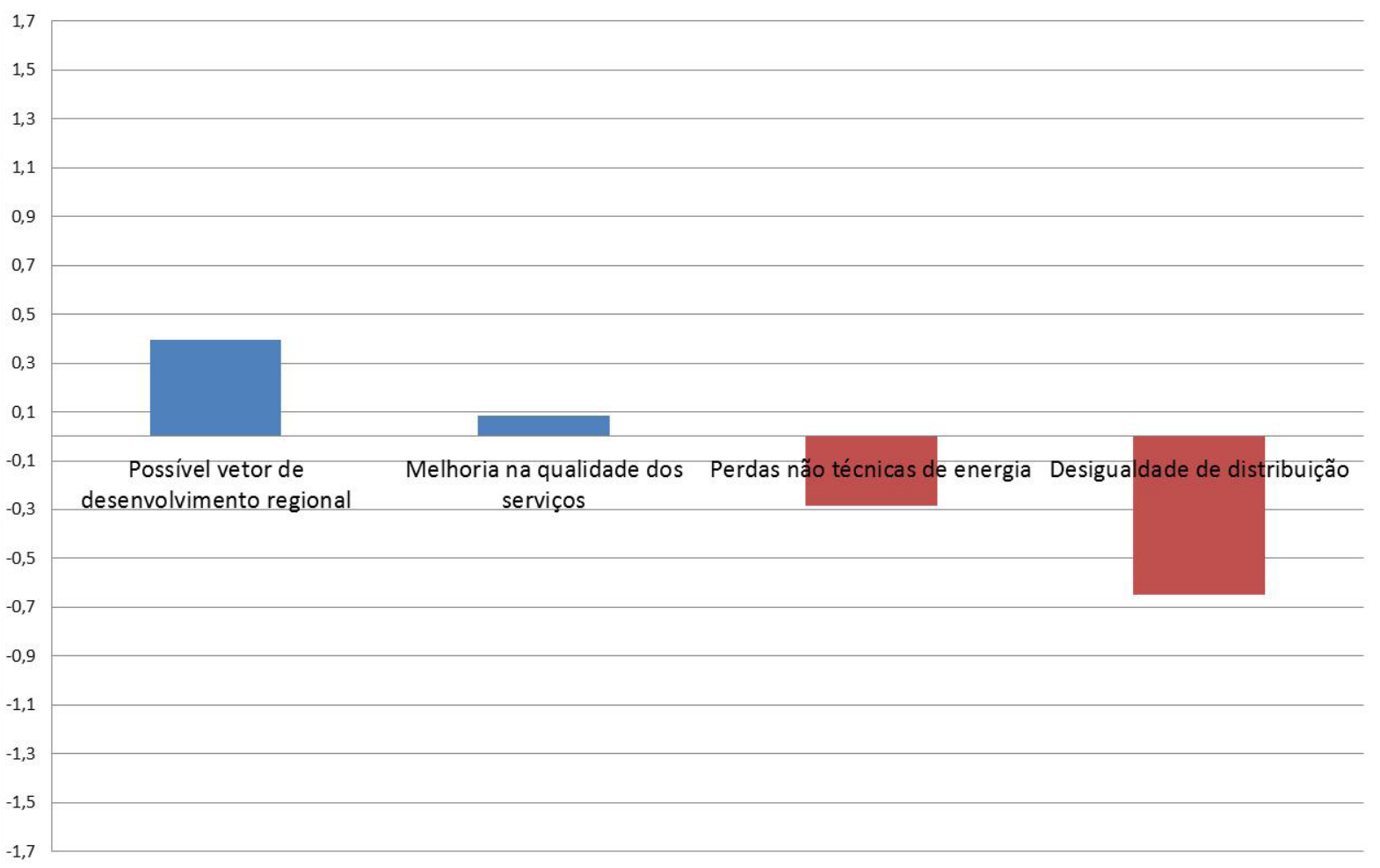

FIGURA 5 - Índice de Significância da Cadeia de PCHs - Distribuição.

Legenda: Azul = Potencialidade para o desenvolvimento da Energia por PCHs; Vermelho = Limitante para o desenvolvimento da Energia por PCHs.

NOTA: Cálculos produzidos a partir dos itens da metodologia e do resultado detalhado no Apêndice 1.

permitir a intermediação, ou a venda direta, aos consumidores e distribuidores, tendo por objetivo flexibilizar e dar efetividade ao mercado competitivo de energia elétrica. No Brasil, o Governo estabeleceu em 2004 um novo marco regulatório buscando revitalizar o setor, sendo que, conforme disposto na Lei $\mathrm{n}^{\mathrm{o}} 10.848$, de 15 de março de 2004, a instituição responsável por viabilizar as atividades de comercialização de energia elétrica e zelar pelo funcionamento do mercado é a Câmara de Comercialização de Energia Elétrica (CCEE) (Brasil, 2004).

O setor elétrico nacional possui dois ambientes de contratação de energia: o Ambiente de Contra- tação Livre (ACL) e o Ambiente de Contratação Regulado (ACR). O primeiro permite a compra da energia diretamente do produtor ou de um agente intermediário, por meio de contratos bilaterais, onde prevalece a livre negociação de preço, qualidade e demanda. Já no segundo, são realizados leilões públicos para a contratação de energia. Neste ambiente, os contratos estabelecidos são de longo prazo, sendo que a CCEE é responsável por operacionalizar os leilões, enquanto que a ANEEL é encarregada de realizá-los (Ferreira, 2013, p. 6; CERPCH, 2015b).

No ACR, o MME determina a data dos leilões, que são realizados pela ANEEL e pela CCEE. O 
preço-teto para o MWh a ser ofertado é fixado por meio de portarias, de acordo com a fonte da energia. Como as geradoras entram em pool (ou seja, a oferta não é individualizada), a prioridade é concedida ao vendedor que pratica o menor preço, sendo que os valores máximos devem ser iguais ou inferiores ao preço-teto (ANEEL, 2008, p. 19).

As PCHs perderam espaço nos leilões de fonte alternativa, sendo que enquanto a sua participação relativa passou de $28 \%$ para menos de $3 \%$, de 2007 a 2010, a participação da fonte eólica elevou-se de $39 \%$ para $80 \%$ (Rego, 2012, p. 121). De acordo com Rego (2012, p. 121), o número reduzido de projetos de $\mathrm{PCH}$ disponíveis para o leilão do ACR é resultado das barreiras enfrentadas por essa fonte no processo de licenciamento ambiental e da sobrecarga de trabalho da ANEEL, com o trâmite de mais de 2.500 estudos de aproveitamentos hidrelétricos. Ademais, o baixo preço praticado no ambiente regulado fez com que houvesse direcionamento desses projetos ao atendimento exclusivo do mercado livre.

Além do preço-teto baixo no ACR, as PCHs podem enfrentar dificuldades na venda de energia para consumidores livres no ACL. Isto porque o contrato firmado pode resultar em exposições extremamente negativas no volátil mercado de curto prazo para o gerador, caso este tenha uma produção de energia menor que seu compromisso de entrega ao consumidor, fato comum no período seco do ano (Fonseca, 2009, p. 16). O mercado do curto prazo (spot) é o ambiente onde são liquidadas as diferenças (positivas ou negativas) entre os montantes de energia contratados e os efetivamente consumidos ou produzidos pelos agentes (Moraes, 2010, p. 43; Tatemoto, 2013, p. 13).

Diante da volatilidade do mercado, como forma de mitigar parte dos riscos hidrológicos, as PCHs podem optar pela participação no Mecanismo de Realocação de Energia (MRE). Este dispositivo visa compartilhar os riscos que afetam os agentes de geração e busca garantir a otimização dos recursos hidrelétricos do SIN. De acordo com a CCEE (2015), o MRE realoca contabilmente a energia, transferindo o excedente daqueles que geraram, além de sua garantia física para aqueles que geraram abaixo. A troca de energia entre os participantes do grupo é feita pela Tarifa de Otimização (TEO), fixada pela Aneel (Pimentel, 2012, p. 107). A TEO fixada para o ano de 2014 era de $\mathrm{R} \$ 10,54 / \mathrm{MWh}$, já para 2015 foi de R\$11,25/MWh (ANEEL, 2013; 2014).

No mercado livre, a energia contratada pode ser convencional ou incentivada. A energia convencional é proveniente de fontes como usinas térmicas a gás ou grandes hidroelétricas. Já a energia incentivada foi estabelecida pelo Governo para estimular a expansão de geradores de fontes renováveis limitados a $30 \mathrm{MW}$ de potência, tais como as PCHs (Mercado Livre de Energia, 2015). A compra e venda de energia incentivada, regulamentada pela Resolução Normativa $n^{\circ} 247$, de 21 de dezembro de 2006, contempla preços livremente negociados entre as partes e é formalizada por meio de Contratos de Compra e Venda de Energia Incentivada (CCEIs). De acordo com a Resolução, o CCEI é celebrado entre o agente gerador incentivado e o consumidor especial (ANEEL, 2006; Tatemoto, 2013, p. 2).

Tatemoto (2013, p. 126) afirma que uma outra forma de mitigar o risco de comercialização da energia incentivada seria por meio de hedge contratual entre fontes incentivadas. Segundo Tatemoto (2013, p. 126), quando duas usinas comercializam energia em conjunto, tais como uma $\mathrm{PCH}$ com uma usina eólica ou uma $\mathrm{PCH}$ com uma termelétrica a biomassa, obtém-se um retorno financeiro maior do que quando a comercialização é realizada de forma isolada. 
A Figura 6 demonstra que tanto as potencialidades quanto os limitantes na etapa da distribuição não são significativos pelos mesmos motivos da transmissão. São quatro fatores, sendo duas potencialidades e dois limitantes. Os limitantes destacados são volatilidade no mercado de curto prazo e preço-teto baixo praticado no ACR, enquanto as potencialidades são possível mecanismo de realocação de energia e energia incentivada. O destaque nesta etapa é a regulamentação do mercado como principal limitante que define, inclusive, um preço-teto baixo. Contudo, só não é mais significativa porque se trata de um tema de curto prazo e cíclico, ou seja, limita, mas pode ser solucionado.

\subsection{Limites, potencialidades e proposições}

Todos os limites e potencialidades identificados neste trabalho apresentam algum nível de significância para o desenvolvimento da cadeia produtiva das PCHs no Brasil. Entretanto, alguns foram considerados mais significativos que outros, com base nos valores dos seus ISs. De todos os limites e potencialidades mapeados, $40 \%$ foram classificados como pouco significativos, $38 \%$ como significativos e $22 \%$ como muito significativos.

Os limites muito significativos, ou seja, aqueles com o valor do IS igual ou menor que $-0,64$, foram quatro: Licenciamento Ambiental; Interfe-

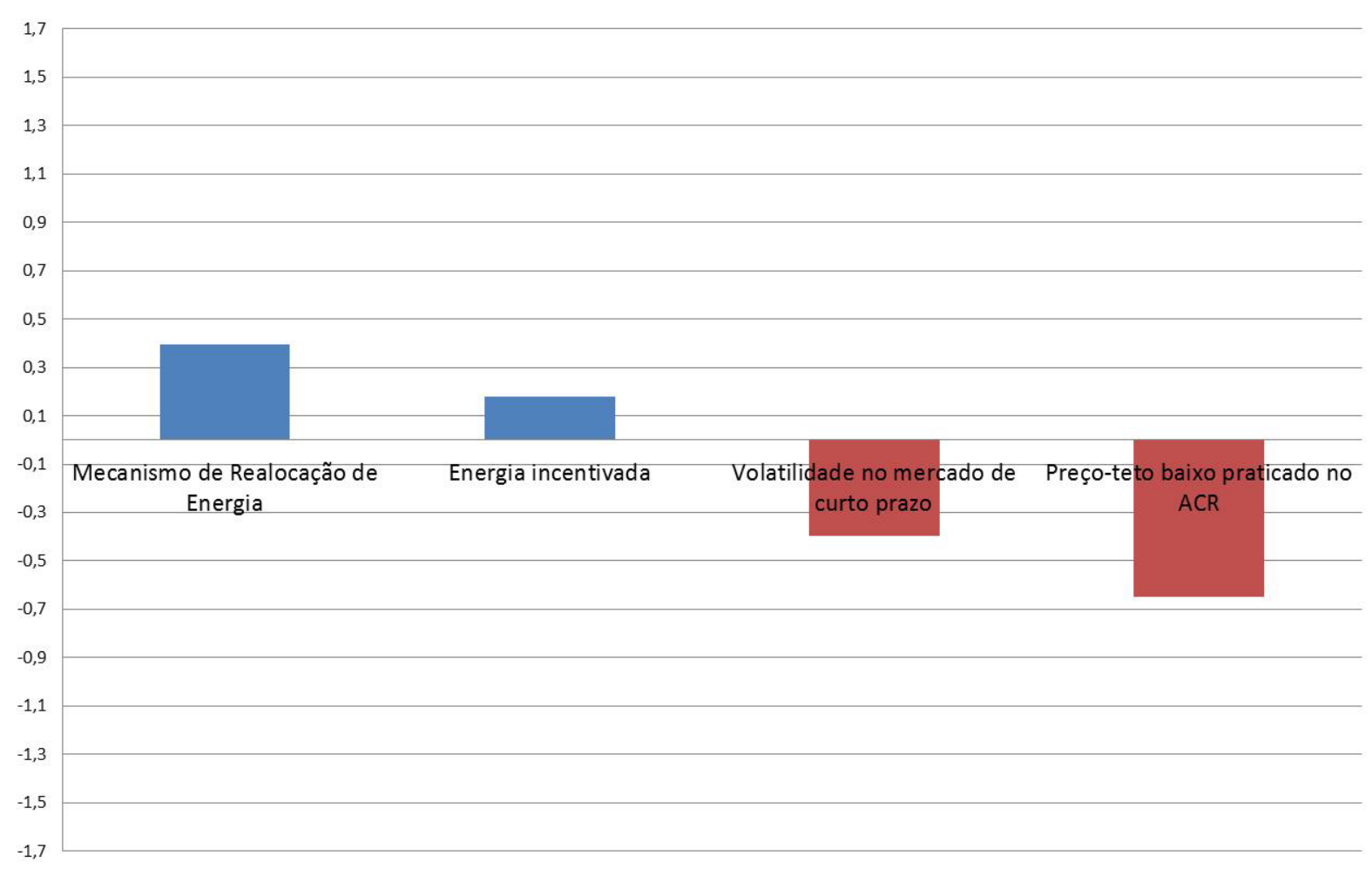

FIGURA 6 - Índice de Significância da Cadeia de PCHs - Comercialização.

Legenda: Azul = Potencialidade para o desenvolvimento da Energia por PCHs; Vermelho = Limitante para o desenvolvimento da Energia por PCHs.

NOTA: Cálculos produzidos a partir dos itens da metodologia e do resultado detalhado no Apêndice 1. 
rência na migração e na reprodução da ictiofauna continental; Desigualdade de distribuição e Preço-teto baixo praticado no ACR. Já as potencialidades classificadas como muito significativas foram quatro também $(>+0,64)$ : Potencial hidrelétrico das bacias hidrográficas; Possível vetor de desenvolvimento regional; Consolidação dos fabricantes de turbinas e geradores e Livre acesso à rede.

$\mathrm{O}$ licenciamento ambiental apresentou o maior valor do IS e foi identificado como um dos principais gargalos da cadeia produtiva das PCHs. Embora seja extremamente relevante, não apenas para instrumentalizar a gestão ambiental, mas também para buscar a harmonia entre o desenvolvimento socioeconômico com a proteção do meio ambiente, a demora na análise dos relatórios e na emissão das licenças, por parte dos órgãos ambientais responsáveis, devido ao significativo volume de solicitações, tem gerado atrasos nos inícios das obras. Além dos desvios no planejamento de implantação e entrega das usinas, os atrasos no cronograma decorrentes de questões que não dependem do empreendedor elevam os riscos do negócio e, por conseguinte, desestimulam a participação de investidores.

Diante deste cenário, sugere-se que, para reduzir a significância deste gargalo, o sistema de licenciamento ambiental seja modernizado, visando à melhoria da capacidade de atuação e resposta dos órgãos ambientais.

Outro limite enquadrado como muito significativo foi a interferência na migração e na reprodução da ictiofauna continental causadas pelo represamento dos rios devido à ameaça de conservação da fauna de peixes. Além disso, a sinergia existente entre a alteração no processo migratório e a modificação na qualidade da água superficial podem vir a comprometer a atividade pesqueira de populações ribeirinhas, afetando a qualidade de vida destas pessoas.
Uma forma de tentar reduzir a sua significância seria por meio de levantamentos mais aprofundados da ictiofauna da região afetada, além da instalação de turbinas que apresentem baixa taxa de mortalidade dos peixes que passarem por elas. Ademais, seria interessante o desenvolvimento de programas que incentivem a pesca consciente entre os pescadores locais.

Já a desigualdade da distribuição de energia no país, apesar de não estar diretamente relacionada às PCHs, também foi considerada um limite muito significativo, tendo em vista que a falta de energia em uma sociedade resulta em assimetrias sociais nas condições de vida. Entretanto, este limite pode ser mitigado pela potencialidade de as $\mathrm{PCH}$ atuarem como vetores de desenvolvimento regional. Desta forma, apesar de mais de 500 mil domicílios rurais no Brasil ainda não terem acesso à eletricidade, a localização das usinas, muitas vezes próximas às comunidades isoladas, não apenas facilita o acesso à energia elétrica gerada, mas também diminui as perdas do sistema e reduz os custos do empreendedor com linhas de transmissão. As PCHs podem, ainda, estimular o mercado local, por meio da possibilidade de geração de emprego e renda temporários.

Outro gargalo considerado muito significativo foi o baixo valor do preço-teto das PCHs praticado nos leilões do ACR, pois, além de desestimular os agentes do setor, que acabam direcionando seus projetos ao atendimento exclusivo do mercado livre, também reduz a competição no ambiente regulado. Consequentemente, para incitar a participação no ACR seria necessária a adoção de preços-teto adequados, que considerem os custos reais envolvidos, tal como o valor do contrato do PROINFA, e possivelmente a realização de leilões específicos para cada tipo de fonte, diante da dificuldade das PCHs em competirem com os baixos preços das outras fontes de energia. 
Já no que tange ao potencial hidrelétrico das bacias hidrográficas brasileiras, apesar da crise no sistema hidrológico do país desde 2012, que tem prejudicado não apenas o abastecimento de água, mas também o fornecimento de energia, ele é considerado uma das potencialidades mais significativas da cadeia. A sua significância está diretamente relacionada com o fato de as PCHs dependerem fundamentalmente da disponibilidade de água para funcionar.

Por fim, a consolidação dos fabricantes nacionais de turbinas e geradores foi posicionada também como uma potencialidade muito significativa, diante da não necessidade de importação de equipamentos de outros países. Ademais, além da compra de produtos manufaturados no país estimular o mercado nacional, a tecnologia utilizada nas hidrelétricas é considerada madura e consolidada, facilitando o domínio tecnológico.

\section{Conclus̃̃es}

Com base nos resultados apresentados e nas análises realizadas observa-se que, apesar de a cadeia de produção das $\mathrm{PCHs}$ possuir diversos gargalos que podem interferir na instalação de novas usinas, este tipo de empreendimento ainda se constitui como uma opção viável para a diversificação da matriz energética nacional. A construção de PCHs no país, de forma sustentável, pode contribuir para o desenvolvimento de comunidades isoladas, sem que grandes áreas sejam alagadas e muitas pessoas tenham que ser reassentadas, além de contribuir com o Sistema Elétrico Interligado Nacional (SIN).

Por meio da pesquisa, foram identificados 37 itens relevantes ao longo da cadeia, sendo 12 na etapa de recursos naturais, oito na geração, quatro na comercialização, nove na transmissão e quatro na distribuição de energia. A partir da análise da cadeia produtiva de $\mathrm{PCHs}$, pode-se identificar os principais aspectos para auxiliar na avaliação da sustentabilidade da cadeia no Brasil e na proposição de formas de minimizar a significância dos gargalos existentes.

Considerando os fatores identificados em cada etapa da cadeia, pode-se potencializar esforços nos limitantes e explorar as potencialidades, especialmente daquelas mais significativas para o desenvolvimento das $\mathrm{PCHs}$ no Brasil. É necessário observar os fatores considerados intermediários ou pouco significativos, mas o risco de influenciar no desenvolvimento de novas PCHs é baixo. Com isso, dos 37 fatores identificados ao longo da cadeia, há, em essência, oito que devem ser considerados para se tomar ações e os demais seriam objetos de monitoramento. Estes oito fatores seriam: licenciamento ambiental; interferência na migração e na reprodução da ictiofauna continental; desigualdade de distribuição; preço-teto baixo praticado no ACR; potencial hidrelétrico das bacias hidrográficas; possível vetor de desenvolvimento regional; consolidação dos fabricantes de turbinas e geradores e livre acesso à rede. Estes fatores orientariam a formalização de uma política pública, considerando que o tema está na agenda política como uma das prioridades do Plano Nacional de Energia. Todavia, é necessário definir melhor o posicionamento político e as ações pertinentes da política pública referentes a cada um destes fatores prioritários.

\section{Agradecimentos}

Agradecemos o apoio financeiro ao projeto "Energia Renovável e Desenvolvimento Regional", financiado pelo CNPq (Edital Universal) - processo 442782/2014-4, e ao projeto de cooperação entre Brasil-Cuba (MES CUBA) pela concessão de bolsas e apoio financeiro. 


\section{Referências}

ABRADEE - Associação Brasileira de Distribuidores de Energia Elétrica. A distribuição de energia, 2015. Disponível em: <http://www.abradee.com.br/setor-de-distribuicao/a-distribuicao-de-energia $>$. Acesso em: jan. 2015.

ANA - Agência Nacional das Águas. Conjuntura dos recursos hídricos no Brasil, 2013. Disponível em: <http:// arquivos.ana.gov.br/institucional/spr/conjuntura/PDFs $\% 20$ agregados/ANA_Conjuntura_Recursos_Hidricos_Brasil_capitulos_.pdf $>$. Acesso em: jan. 2015.

ANEEL - Agência Nacional de Energia Elétrica. Resolução $n^{\circ} 281$, de 01 de outubro de 1999. Disponível em: <http:// www.aneel.gov.br/aplicacoes/audiencia/arquivo/2005/010/ documento/resolucao_n\%C2\%BA_281_1999_-versao_ proposta_com_alteracoes.pdf $>$. Acesso em: jan. 2015.

ANEEL - Agência Nacional de Energia Elétrica. Decreto $n^{\circ}$ 4.873, de 11 de novembro de 2003. Disponível em: $<\mathrm{http}: / /$ www.aneel.gov.br/cedoc/bdec20034873.pdf > . Acesso em: jan. 2015.

ANEEL - Agência Nacional de Energia Elétrica. Energia Hidráulica. Atlas de Energia Elétrica, 2003. Disponível em: <http://www.aneel.gov.br/aplicacoes/atlas/pdf/04-Energia_Hidraulica(2).pdf>. Acesso em: maio 2014.

ANEEL - Agência Nacional de Energia Elétrica. Resolução $n^{\circ} 247$, de 21 de dezembro de 2006. Disponível em: $<$ http://www.aneel.gov.br/cedoc/ren2006247.pdf $>$. Acesso em: fev. 2015.

ANEEL - Agência Nacional de Energia Elétrica. Atlas de Energia Elétrica do Brasil. 2008. Disponível em: <http:// www.aneel.gov.br/arquivos/PDF/atlas3ed.pdf $>$. Acesso em: jan. 2015.

ANEEL - Agência Nacional de Energia Elétrica. Evolução da capacidade instalada, 2013. Disponível em: <http:// www.aneel.gov.br/aplicacoes/capacidadebrasil/capacidadebrasil.cfm>. Acesso em: set. 2013.

ANEEL - Agência Nacional de Energia Elétrica. Distribuição de Energia Elétrica, 2015. Disponível em: <http://www. aneel.gov.br/area.cfm?idArea=77>. Acesso em: jan. 2015.

ANEEL - Agência Nacional de Energia Elétrica. Banco de Informações de Geração (BIG), 2016. Disponível em:
$<$ http://www.aneel.gov.br/aplicacoes/capacidadebrasil/ capacidadebrasil.cfm>. Acesso em: abr. 2016.

Andrade, E. de S.; Araújo, J. da C. Medidas mitigadoras dos impactos ambientais causados por usinas hidrelétricas sobre peixes. Revista Eletrônica de Veterinária, 12(3), 1-30, 2011.

Ardizzon, G. et al. A new generation of small hydro and pumped-hydro power plants: Advances and future challenges. Renewable and Sustainable Energy Reviews, 31, 746-761, 2014.

Barbosa, P. S. F. et al. Cheias em vales inundáveis à jusante de usinas hidrelétricas. Revista Pesquisa e Desenvolvimento da ANEEL, 4, 2011. Disponível em: <http://www.aneel.gov. br/arquivos/PDF/revista_P\&D_04_web.pdf $>$.

Bermann, C. Impasses e controvérsias da hidroeletricidade. Estudos Avançados. 21(59), 139-153, 2007.

Brasil. Lei ${ }^{\circ} 6.938$, de 31 de agosto de 1981. Dispõe sobre a Política Nacional do Meio Ambiente. Brasília: DOU de 2/9/1981.

Brasil. Lei $n^{\circ}$ 9.074, de 7 de julho de 1995. Estabelece normas para outorga e prorrogações das concessões e permissões de serviços públicos e dá outras providências Brasília: DOU de 8/7/1995.

Brasil. Lei $n^{\circ} 10.438$, de 26 de abril de 2002. Dispõe sobre a expansão de energia elétrica emergencial e outros afins. Brasília: DOU de 29/4/2002.

Brasil. Lei $n^{\circ} 10.848$, de 15 de março de 2004. Dispõe sobre a comercialização da energia elétrica. Brasília: DOU de $16 / 3 / 2004$.

Capellesso, A. J.; Cazella, A. A. Pesca artesanal entre crise econômica e problemas socioambientais: estudo de caso nos municípios de Garopaba e Imbituba (SC). Ambiente \& Sociedade, 14(2), 15-33. 2011. Disponível em: <http:// www.scielo.br/pdf/asoc/v14n2/03.pdf>.

Carvalho, D. F. et al. Hidrologia. Irrigação e Drenagem, 2007. Disponível em: <http://www.ufrrj.br/institutos/it/ deng/jorge/downloads/APOSTILA/LICA\%20Parte\%201. pdf $>$. Acesso em: jul. 2014.

CERPCH - Centro Nacional de Referência em Pequenas Centrais Hidrelétricas. Fabricantes de turbinas hidráulicas. 
Disponível em: $<$ http://www.cerpch.unifei.edu.br/fabricantes-de-turbinas-hidraulicas.html>. Acesso em: jan. 2015a.

CERPCH - Centro Nacional de Referência em Pequenas Centrais Hidrelétricas. Mercado de PCH, 2015. Disponível em: $<$ http://www.cerpch.unifei.edu.br/mercado_pch.php $>$. Acesso em: jan. 2015b.

ELETROBRÁS - Centrais Elétricas Brasileiras S.A. Fluxogramas de atividades para estudos e projetos, 2005. Disponível em: <https://www.eletrobras.com/ELB/ services/DocumentManagement/FileDownload.EZTSvc. asp?DocumentID=\%7B54DA2095-47F9-46F7-BE76-B347 $\mathrm{CA} 486 \mathrm{AC} 3 \% 7 \mathrm{D} \&$ ServiceInstUID $=\%$ 7B3C6E3C0E-2ADA4EE5-B8F5-647119AA05CB\%7D>. Acesso em: nov. 2014.

ELETROBRÁS - Centrais Elétricas Brasileiras S.A. Potencial hidrelétrico brasileiro por bacia, 2014. Disponível em: <http://www.eletrobras.com/elb/data/Pages/LUMIS21D128D3PTBRIE.htm>. Acesso em: nov. 2014.

EPE - Empresa de Pesquisa Energética. Plano Decenal de Expansão de Energia 2022. 2013. Disponível em: <http:// www.epe.gov.br/PDEE/20140124_1.pdf>. Acesso em: 10 mar. 2014.

EPE - Empresa de Pesquisa Energética. Balanço Energético Nacional (BEN). Relatório Síntese. 2014 (ano base 2013). 2014. Disponível em: <https://ben.epe.gov.br/downloads/ S\%C3\%ADntese\%20do\%20Relat\%C3\%B3rio\%20Final_2014_Web.pdf>. Acesso em: abr. 2014.

EPE - Empresa de Pesquisa Energética. Custo Marginal de Expansão: Metodologia de Cálculo 2011. 2011. Disponível em: <http://www.epe.gov.br/geracao/Documents/ Estudos_26/NT_MetodologiadeCalculoCME_2011.pdf>. Acesso em: set. 2013.

Faria, F. A. M. de. Metodologia de prospecção de pequenas centrais hidrelétricas. São Paulo, Dissertação (Mestrado em Engenharia) - Universidade de São Paulo, 2011.

Ferreira, L. E. B. Cenário e tarifas do mercado livre e regulado. 2013. Disponível em: <http://www.abraceel.com. br/zpublisher/paginas/ccee_apresentacoes.asp?pag=2>. Acesso em: abr. 2016.

Fonseca, F. R. Estratégias de sazonalização da garantia fisica de PCHs em portfólios PCHs e biomassa. Rio de Janeiro, Dissertação (Mestrado em Engenharia Elétrica) - Pontifícia Universidade Católica do Rio de Janeiro, Rio de Janeiro, 2009.
Fontes, G. do A. et al. Princípio fundamental ao meio ambiente: pequenas centrais hidrelétricas na matriz energética brasileira. Revista Constituição e Garantia de Direitos, 1(4), 1-23, 2010. Disponível em: <http://ojs.ccsa.ufrn.br/index. php/cgd/article/view/180/183>.

Francisco, C. M. Connecting renewable power plant to the Brazilian transmission power system. The Institute of Brazilian Business and Public Management Issues. 2012. Disponível em: <http://www.aneel.gov.br/biblioteca/trabalhos/trabalhos/Artigo_Cecilia_Francisco.pdf $>$. Acesso em: jan. 2015.

Hernandes Junior, L. et al. Processo não invasivo de baixo custo para otimização da rotina de inspeção na detecção de furto de energia elétrica. Revista Pesquisa e Desenvolvimento da ANEEL, 1(5), 48-51, 2013. Disponível em: <http:// www.aneel.gov.br/biblioteca/downloads/livros/Revista\%20 P\&D_05.pdf>.

IAP - Instituto Ambiental do Paraná. Estudo de Impacto Ambiental (EIA): PCH Água Limpa, 2011. Disponível em: $<$ http://www.iap.pr.gov.br/modules/conteudo/conteudo. php? conteudo=1366>. Acesso em: jan. 2015.

ICSHP - International Center on Small Hydro Power. World Small Hydro Power Development Report. 2013. Disponível em: <http://www.smallhydroworld.org/fileadmin/user_upload/pdf/WSHPDR_2013_Final_Report-updated_version.pdf $>$. Acesso em: maio 2014.

INEPAR. IESA participa dos mais importantes empreendimentos de energia elétrica do mundo. 2014. Disponível em: <http://www.inepar.com.br/not_uhe_santonio.htm>. Acesso em: jul. 2014.

Instituto ABRADEE. Módulo 4 - Transmissão. 2010. Disponível em: <http://www.eletrobrasroraima.com/ wp-content/uploads/2011/01/M\%C3\%93DULO-4TRANSMISS\%C3\%83O.pdf>. Acesso em: jan. 2015.

Jannuzzi, G. de M. Faltam politicas públicas para eficiência energética e fontes renováveis: entrevista de 09 dez. 2010 no Ecodebate/Instituto Humanitas Unisinos - IHU da Universidade do Vale do Rio dos Sinos (Unisinos) em São Leopoldo, 2010. Disponível em: <http://www. ecodebate.com.br/2010/12/09/faltam-politicas-publicas-para-eficiencia-energetica-e-fontes-renovaveis-entrevista-com-gilberto-de-martino-jannuzzi/>. Acesso em: set. 2014. 
Kusma, C. M.; Ferreira, F. W. Mecanismo de transposição de peixes de pequena central hidrelétrica. Ciência Rural, 40(1), 89-94, 2010. doi: 10.1590/S0103-84782009005000247

Leão, L. L. Considerações sobre impactos socioambientais de Pequenas Centrais Hidrelétricas (PCHs): modelagem e análise. Brasília, Dissertação (Mestrado em Desenvolvimento Sustentável) - Universidade de Brasília, Distrito Federal, 2008.

Makaron, P. M. Análise de viabilidade de projetos de pequenas centrais hidrelétricas: pontos críticos de sucesso a partir de estudos de caso no Estado de Santa Catarina. São Paulo, Dissertação (Mestrado em Energia) - Universidade de São Paulo, 2012.

Manzano-Agugliaro, F. et al. Scientific production of renewable energies worldwide: An overview. Renewable and Sustainable Energy Reviews, 18, 134-143, 2013. doi: 10.1016/j.rser.2012.10.020

Mercado Livre de Energia. Visão geral, 2015. Disponível em: <http://www.mercadolivredeenergia.com.br/>. Acesso em: jan. 2015.

MME - Ministério de Minas e Energia. Manual de Inventário Hidroelétrico de Bacias Hidrográficas, 2007. Disponível em: <http://www.biblioteca.presidencia.gov. br/publicacoes-oficiais-1/catalogo/conselhos/conselho-nacional-de-politica-energetica/manual-de-inventario-hidroeletrico-de-bacias-hidrograficas/view>. Acesso em: jan. 2015.

Moraes, B. Z. Análise econômico-financeira de uma Pequena Central Hidrelétrica (PCH). Porto Alegre, Monografia (Bacharelado em Administração) - Departamento de Ciências Administrativas, Universidade Federal do Rio Grande do Sul, 2010.

Nadaud, G. C. A. Acesso à energia elétrica de populações urbanas de baixa renda: o caso das favelas do Rio de Janeiro. Rio de Janeiro, Dissertação (Mestrado em Planejamento Energético)-Universidade Federal do Rio de Janeiro, 2012.

Nascimento Junior, J. S.; Gopfert, L. C. Impactos ambientais pela implantação da linha de transmissão $500 \mathrm{kV}$ Oriximiná-Cariri.Rio de Janeiro, Monografia (Graduação em Engenharia Ambiental) - Universidade Federal do Rio de Janeiro, 2010.
OCDE. Handbook on constructing composite indicators: Methodology and user guide, 2008. Disponível em: $<$ http:// www.oecd.org/std/42495745.pdf > . Acesso em: abr. 2016.

Pérez, V. E et al.. Composite indicator for the assessment of sustainability: The case of Cuban nature-based tourism destinations. Ecological Indicators, 29, 316-324, 2013. doi: 10.1016/j.ecolind.2012.12.027

Perius, M. R.; Carregaro, J. B. Pequenas Centrais Hidrelétricas como forma de redução de impactos ambientais e crises energéticas. Ensaios e Ciência: Ciências Biológicas, Agrárias e da Saúde, 16(2), 135-150, 2012. Disponível em: $<$ http://www.redalyc.org/articulo.oa?id=26025448011>

Pimentel, R. PCHs: é necessário investir mais nesta alternativa. TN Petróleo, 3(21), 106-107, 2012. Disponível em: $<$ http://www.tnsustentavel.com.br/biblioteca/download/ id/129/f/pchs-e-necessario-investir-mais-nesta-alternativa-_artigo--116-kb--pdf>.

Pinto Junior, H. Q. et al. Economia da energia: fundamentos econômicos, evolução histórica e organização industrial. Rio de Janeiro: Elsevier, 2007.

Portal Brasil. Rede de transmissão supera 107 mil quilômetros, 2011. Disponível em: <http://www.brasil.gov.br/ infraestrutura/2011/12/rede-de-transmissao-supera-107-mil-quilometros>. Acesso em: jan. 2015.

Portos e Navios. Importação de fios e cabos aumenta e afeta companhias, 2014. Disponível em: <http://portosenavios. com.br/geral/23533-importacao-de-fios-e-cabos-aumenta-e-afeta-companhias>. Acesso em: jan. 2015.

PNUD - Programa das Nações Unidas para o Desenvolvimento. ONU quer universalizar energia até 2030, 2011. Disponível em: <http://www.pnud.org.br/Noticia. aspx?id=2439>. Acesso em: jan. 2015.

Rego, E. E. Proposta de aperfeiçoamento da metodologia dos leilões de comercialização de energia elétrica no ambiente regulado: aspectos conceituais, metodológicos e suas aplicações. São Paulo, Tese (Doutorado em Energia) - Universidade de São Paulo, São Paulo, 2012.

Reis, L. B. dos. Geração de energia elétrica: tecnologia, inserção ambiental, planejamento, operação e análise de viabilidade. 3 ed. São Paulo: Manole Ltda., 2003.

Ribeiro, M. G. Metodologia de cálculo de custos em linhas de transmissão no Brasil. Rio de Janeiro, Monografia (Gra- 
duação em Engenharia Elétrica) - Universidade Federal do Rio de Janeiro, Rio de Janeiro, 2014.

Sales, C. J. D. Os enormes desafios da transmissão de energia, 2011. Disponível em: <http://www.andradecanellas.com.br/default.asp?id_materia $=9141>$. Acesso em: jan. 2015.

Sauer, I. L. et al.. Energias renováveis: ações e perspectivas na Petrobras. Bahia Análise \& Dados, 16(1), 9-22, 2006. Disponível em: $<$ http://www.sei.ba.gov.br/index. php?option $=$ com_content $\&$ view $=$ article $\&$ id $=1234 \&$ Item $\mathrm{id}=110>$.

Silva, N. F. da. Fontes de energia renováveis complementares na expansão setor elétrico brasileiro: o caso da energia eólica. Rio de Janeiro, Tese (Doutorado em Planejamento Estratégico) - Universidade de Rio de Janeiro, Rio de Janeiro, 2006.

Souza, A.; Silva, C. L. Energia e meio ambiente: o trade-off entre as matrizes energéticas de fontes renováveis e não renováveis no Brasil. Revista Terceiro Incluído, 2(2), 63-84, 2012. Disponível em: <http://revistas.ufg.emnuvens. com.br/teri/article/view/23290>.

Souza, C. J. Determinação da largura de faixa de segurança de linhas de transmissão: um estudo paramétrico. Belo Horizonte, Dissertação (Mestrado em Engenharia Elétrica) - Universidade Federal de Minas Gerais, 2012.

Souza, P. A. P. et al. Planejamento e Gestão Ambiental Integrada quando da implantação de PCHs, 2001. Disponível em: $<$ http://www.researchgate.net/publication/237794405 PLANEJAMENTO_E_GESTO_AMBIENTAL_INTEGRADA_QUANDO_DA_IMPLANTAO_DE_PEQUENAS_CENTRAIS_HIDRELTRICAS_\% $\overline{2} 8 \mathrm{PCH} \% 29>$. Acesso em: jan. $20 \overline{15}$.
Tatemoto, K. A. Energia incentivada: uma análise integrada dos aspectos regulatórios, de comercialização e de sustentabilidade. São Paulo, Dissertação (Mestrado em Ciências) - Universidade de São Paulo, São Paulo, 2013.

The World Bank. Databank: Access to electricity (\% of population), 2016.Disponível em: <http://data.worldbank.org/ indicator/EG.ELC.ACCS.ZS/countries?display=graph>. Acesso em: abr. 2016.

Vadas, R. G. Segurança e rompimento de barragens, 2014. Disponível em: <http://www.asec.com.br/000111201asec/ ArquivoAMR/EncontroTecnico/IISeminarioAguaEnergia2014/26/IISeminarioAguaEnergia20140007.pdf>. Acesso em: jan. 2015.

Vergílio, K. E. P. Geração distribuída e pequenas centrais hidrelétricas: alternativas para a geração de energia elétrica no Brasil. São Paulo, Monografia (Graduação em Engenharia Elétrica) - Universidade de São Paulo, São Carlos, 2012.

Vianna, J. N. de S.. Energia e meio ambiente no Brasil. In: Bursztyn, M. (Org.). A dificil sustentabilidade. Rio de Janeiro: Garamond, 2009.

Vieira, I. S. Expansão do sistema de transmissão de energia elétrica no Brasil. Brasília, Dissertação (Mestrado em Engenharia Elétrica) - Universidade de Brasília, Brasília, 2009.

WCD - World Commission on Dams. Dams and development: a new framework for decision making. 2000. Disponível em: <http://www.internationalrivers.org/files/ attached-files/world_commission_on_dams_final_report. pdf>. Acesso em: jan. 2015.

WWF Brasil. Agenda Elétrica Sustentável 2020: estudo de cenários para um setor elétrico brasileiro eficiente, seguro e competitivo. Série Técnica, vol. XII, 2006. Disponível em: $<$ http://assets.wwf.org.br/downloads/wwf_energia_ebook. pdf $>$. Acesso em: jan. 2015. 


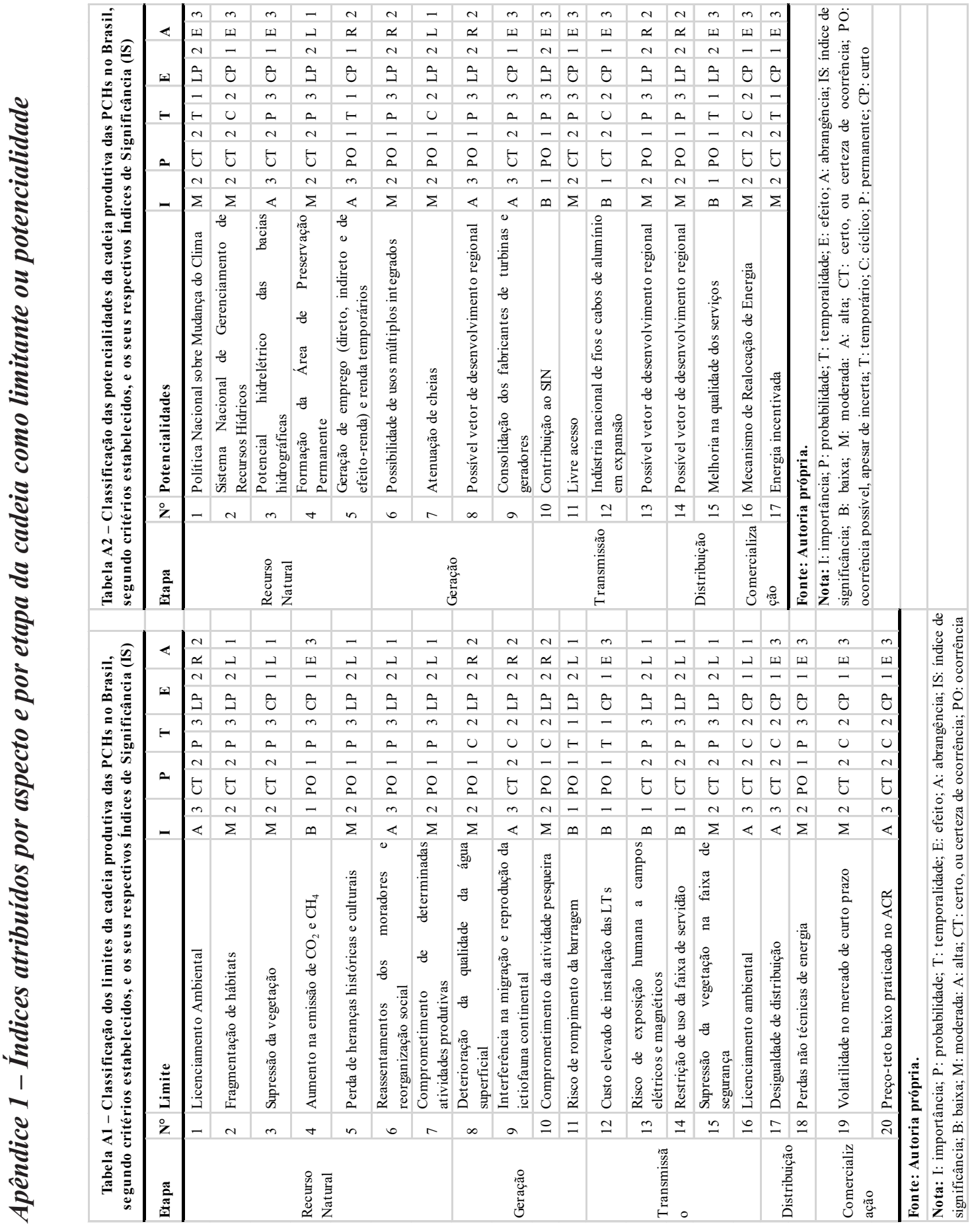

